\title{
Zur Morphologie der Malacostraca: Der Kaumagen der Mysidacea im Vergleich zu dem verschiedener Peracarida und Eucarida
}

\author{
KLAus Haffer \\ Zoologisches Institut der Universität Kiel, Abteilung für Embryologie
}

\begin{abstract}
On the morphology of the Malacostraca: the mastax of the Mysidacea as compared to that of various Peracarida and Eucarida. Anatomy and muscle arrangement of the mastax and the labrum of Neomysis vnlgaris are described. For this purpose the mastax as a whole was made transparent and its chitin preparation then covered with minute silver particles (transfer into a silver salt solution; reduction of the silver) and thus made opaque. A comparison of the upper lip muscular system with that of Diastylis rathkei resulted in agreement with respect to several muscle groups. A comparison of the stomach muscles with corresponding muscles of the decapods - which is possible only to a limited extent - is given in Table 3. On the basis of total preparations of the chitinintima of the stomachs of different eucarid and peracarid representatives, a direct comparison was possible. Within the bounds of the common general morphology of the malacostracan stomach, an isopod type (Amphipoda, Cumacea, Tanaidacea, Isopoda) and a decapod type (Mysidacea, Euphausiacea, Decapoda) are distinguishable. These two types are connected by an intermediate type, which reveals characteristics of both (Lophogastrida). The parts of the stomach which compose the grinding mechanism of the decapods do not represent a special feature of this group, but belong, as do the other parts of the decapod stomach, to the general morphological design of the malacostracan stomach.
\end{abstract}

\section{EINLEITUNG}

Während die Muskulatur der Kaumägen verschiedener Dekapoden schon eingehender beschrieben worden ist, liegen über die entsprechenden Verhältnisse bei anderen Malakostraken nur allgemeine oder begrenzte Angaben vor. Die systematische Bedeutung des Kaumagenkomplexes der Malakostraken läßt es jedoch wünschenswert erscheinen, die Muskelverhältnisse am Magen auch in den anderen Gruppen genauer kennenzulernen. Denn wenn in letzter Zeit gezeigt werden konnte (SIEWING 1957), daß den Kaumägen aller Malakostraken ein gemeinsames Bauprinzip zugrunde liegt, so muß es interessant sein zu erfahren, ob für die Magenmuskulatur der Malakostraken ähnliches gesagt werden kann. Im Hinblick darauf soll in dieser Arbeit zunächst an Neomysis vulgaris (Mysidacea) als einem Vertreter der Basisgruppe der Peracarida die Muskulatur des Magens und, soweit möglich, ihre Funktion beschrieben werden. 
Der Kaumagen der Mysidacea ist bereits untersucht worden (Gelderd 1908). Da jetzt aber die Bearbeitung der Magenmuskulatur eine genauere Kenntnis auch der Magenanatomie mit sich brachte, sei hier auch der Aufbau des Kaumagens von Neomysis vulgaris beschrieben.

Die Methode der Magendarstellung durch Mazeration machte es weiterhin möglich, die Kaumägen der Vertreter verschiedener Malakostrakengruppen an Hand von Totalpräparaten in einer vergleichenden Übersicht zu behandeln.

\section{MATERIAL UND METHODE}

Die untersuchten Neomysis vulgaris stammen aus dem Kleinen Kiel, einem durch Verbindung mit der Kieler Förde brackigen Gewässer in der Kieler Innenstadt, und aus dem Nord-Ostsee-Kanal bei $\mathrm{km}$ 85,5 an der Einmündung der Eider (Schleuse Strohbrück). Zunächst wurde versucht, unter dem Binokular am lebenden Tier die Magentätigkeit zu beobachten. Denn dorsal, hinter den Augen, reicht der Kaumagen bis dicht unter die Körperoberfläche. Selbst bei leerem Magen - auch nach Verabreichung von Carminpulver zur Anfärbung des Mageninneren - waren jedoch von den Magenstrukturen außer dem Umriß der Cardia und der weit in ihr Lumen vorspringenden Lateralfalten keine Einzelheiten zu erkennen. Als einzige Magenbewegung war ein Nach-vorn-unten-Rutschen der Cardia auszumachen, jedoch kein verursachender Muskel. Es mußte also zum Präparat gegriffen werden.

Fixiert wurde in Bouinschem Gemisch, die Einbettung erfolgte über Alkohol, $\mathrm{Me}$ thylbenzoat und Xylol in Paraffin (Schmelzpunkt 570-60 C). Es wurden Schnittserien von 10 bis $200 \mu$ angefertigt, die mit Hämatoxylin DeLAfIELd/Erythrosin, mit der MAssonschen Trichromfärbung nach GoLDNER oder mit Chlorazolblack gefärbt wurden. Teilweise wurde auch vor dem Einbetten in Boraxkarmin totalgefärbt. Im allgemeinen ist es bei dickeren Schnitten günstig, wenn sie nur wenige Bäder zu durchlaufen haben und rasch zur Eindeckung gelangen, da sie zum Abschwimmen neigen. Beim Eindecken ist Malinol von Vorteil gegenüber Caedax, weil sich bei dickeren Schnitten die Verkürzung der Trockenzeit günstig bemerkbar macht.

Die Schnittpräparate ergaben einen plastischen Überblick über den Kaumagen und seine Muskulatur. Um jedoch die Funktion der feineren und derjenigen Muskeln zu erfassen, welche die Magenteile untereinander verbinden, schien es wünschenswert, den Kaumagen als Ganzes betrachten zu können. Das wurde möglich durch folgende Methodik:

(1) M a $\mathrm{z}$ e r a $\mathrm{t}$ i o n des Vorderkörpers ganzer Tiere in 10\% oiger Kalilauge, wobei außer der Körperdecke auch die Magenauskleidung unversehrt bleibt. Bei dieser Behandlung stellte sich heraus, daß nur fixierte Tiere sauber mazeriertes Chitin ergeben, und zwar besonders in Boursshem Gemisch fixierte; einfache Alkoholfixierung reichte nicht aus. Außerdem fiel auf, daß die Tiere aus dem Kleinen Kiel ein formstabileres Chitin aufweisen als die Tiere aus dem Nord-Ostsee-Kanal. Das mag daran liegen, daß das Wasser im Kanal einen höheren Säuregrad hat als im Kleinen Kiel; denn allgemein zeigt sich, daß der Chitinpanzer der Wirbellosen mit steigendem Säuregrad und damit fallendem Kalkgehalt des Biotopwassers weicher wird (Mitteilung von Frl. Dr. L. ScHütz). 
(2) Säuberndes Magens unter dem Binokular mittels Durchspülen mit Hilfe einer 2-ccm-Injektionsspritze (Kanïle 20, spitz). Dazu wird die Chitinhülle des Tieres an den Antennen mit einer Pinzette festgehalten und die Kanülenspitze zwischen die Mandibeln in Richtung Oesophagus gebracht.

(3) $\mathrm{F} \ddot{a} \mathrm{r}$ b e n d e s $\mathrm{Ch}$ it in s mit Anilinblau, wodurch die Strukturen klarer hervortreten, die Durchsichtigkeit aber gewahrt bleibt. Uberfärbung kann mit Kalilauge differenziert werden, da sie den Farbstoff zerstört.

(4) A bspüle n des Farbüberschusses mit Wasser und Abtrennen des Magens am Übergang Oesophagus/Körperdccke mit Hilfe einer Pinzettenschere (Nachstarschere nach VANNAS).

Nach dieser Behandlung ist es möglich, den gesamten Kaumagen, der je nach Größe des Tieres bis zu 1,75 mm lang und bis zu 1,2 $\mathrm{mm}$ breit sein kann, mit seinen komplizierten Falten- und Borstensystemen zu überblicken. Als günstigstes Einschlußmittel für diese Präparate erwies sich Glycerin: die Strukturen treten klar hervor, das Chitin verpilzt nicht und die Überführung in Wasser zur Nachfärbung, falls die Farbe abblaßt, ist direkt möglich; schließlich ist die Schlierenbildung, die die Nadel beim Bewegen des Präparates hervorruft, was das Bild beim Fotografieren stören könnte, gering.

So plastisch und übersichtlich das Innere des Kaumagens jetzt war - das komplizierte Oberflächenrelief des Magens ließ sich bei Durchlicht nur unvollständig erfassen. Es ist nicht möglich, so dünnes und nicht inkrustiertes Chitin so stark anzufärben, daß es undurchsichtig wird. Schließlich gelang es jedoch, den Magen durch Aufbringen einer dünnen Schicht kolloidalen Silbers der Arbeit mit Auflicht zugänglich zu machen und damit die Voraussetzung zu schaffen für eine befriedigende Darstellung der Muskulatur, deren Untersuchung nicht nur an den Schnittpräparaten erfolgte, sondern auch an Präparaten, die besonders für die Constrictormuskeln durch direkte Präparation des Magens unter dem Binokular gewonnen wurden. Zur Versilberung wurde das Präparat in $1 / 10$ normale oder schwächere Silbernitratlösung gebracht, der zur Reduktion einige Tropfen Tanninlösung zugesetzt wurden. Die ausfallenden Silberpartikel haften genügend fest am Chitin. Unter dem Binokular kann dabei die Beschichtungsdicke durch längeres oder kürzeres Belassen im Silberregen beeinflußt werden. Von Wichtigkeit ist noch der Zeitpunkt, zu dem das Reduktionsmittel zugegeben wird: liegt das Präparat schon länger in der Silbersalzlösung, wird es mit dem Zusetzen des Reduktionsmittels schlagartig schwarz und glänzend; läßt man die Reduktion mit dem Einbringen des Präparats in die Silbersalzlösung sofort beginnen, so ist der Effekt insofern ungünstig, als die Silberpartikel zu groß und flockig ausfallen und das Bild unsauber wird; das zweckmäßigste ist, die Reduktion auszulösen, nachdem das Präparat einige Augenblicke in der Silbersalzlösung gelegen hat, denı dann wird die Struktur der Silberschicht feinkörnig und erzeugt keine Lichtreflexe, die besonders beim Fotografieren stören, und außerdem ist der Kontrast der grauen Silberschicht im Hinblick auf einen dunklen Hintergrund am günstigsten. Diesen muß man wählen, weil bei hellem Untergrund an den dünneren Stellen des Magenchitins - da die Silberschicht nicht stark genug ist - Licht durchfallen und die plastische Wirkung aufheben würde.

Nach der Versilberung überführt man in Wasser und weiter in Glycerin oder, zu fotografischen Zwecken, in Celodal, und zwar über 70\%igen Alkohol und eine $\mathrm{Z}_{\mathrm{wi}}$ schenstufe 70\% \%iger Alkohol/Celodal von etwa der halben Konsistenz des reinen Celo- 
dals, da der Magen bei direktem Überführen aus dem Alkohol in Celodal schrumpfen würde. Celodal ist beim Fotografieren das günstigste Einschlußmittel, infolge seiner Konsistenz hält das Präparat am besten seine Lage. Für anilinblau-gefärbte Präparate ist Celodal nicht zu verwenden, da die Farbe zerstört wird.

Die Fotografien wurden hergestellt mit dem Leitz-Aristophot mit Leica, Balgen, Spiegelreflexansatz und 24-mm-Summar. Zur Beleuchtung bei Durchlicht diente die zugehörige Makrodia-Einrichtung, bei Auflicht zur Erzielung der erforderlichen hohen Lichtintensität ein Leitz-Bildwerfer „Prado 250", als Gegenlicht zur Aufhellung der Schattenpartien eine Leitz-Monla-Lampe bei 5,5 Amp. und ein Vakuum-Punktblitz von 300 Wattsekunden. Der Projektor wurde ohne Objektiv verwendet und so gestellt, daß das Licht von links oben auf das Objekt fiel. Das Objekt befand sich dabei in der Brennebene des Kondensors, das heißt in der Ebene, in der das Glühwendel der Projektorlampe abgebildet wird, und zwar in der besonders hellen Zone des Glühfadenbildes selbst. Monla-Lampe und Vakuum-Blitz beleuchteten von der gegenüberliegenden Seite.

Zum Fotografieren lagen die Präparate in einer kleinen Schale, die durch Aufkleben eines Glasringes auf einen Objektträger hergestellt war, um bei Durchlichtaufnahmen einen gleichmäßigen Lichtdurchfall zu gewährleisten. Bei Auflichtaufnahmen bildete ein Stück belichteter Film den gleichmäBig schwarzen Untergrund. Als Aufnahmematerial diente Agfa-Agepe-Film. Es wurde in den meisten Fällen überbelichtet und unterentwickelt. Die Durchlichtaufnahmen und die Zeichnungen wurden über Zwischennegative abgezogen.

\section{DER MAGEN VON NEOMYSIS VULGARIS}

\section{Anatomie des Magens}

Die Mundöffnung liegt ventral zwischen der voluminösen Oberlippe und der Unterlippe mit den beiden Paragnathen, sie führt in den Oesophagus, der schräg nach vorn ansteigt und sich in den Kaumagen öffnet. Dieser ist, wie bei den Dekapoden, deutlich in Cardia und Pylorus geteilt. Die Magenteile sind in vielfältiger Weise mit Chitinborsten und -zähnen bewehrt. Der Magenboden steigt im cardiakalen Teil des Magens schräg nach hinten an - etwa im rechten Winkel zur Oesophagusachse - und fällt im pylorikalen Teil schräg nach hinten ab - etwa parallel zur Oesophagusachse. Das Magendach bläht sich über der Cardia kugelförmig bis dicht unter das dorsale Integument, verläuft über dem Pylorus etwa parallel zur Längsachse des Tieres und setzt sich als rohrförmige Einfaltung noch ein beträchtliches Stiick nach hinten in den Mitteldarm fort (Abb. 1).

Zur Nomenklatur ist zu sagen, daß im Interesse einer zwanglosen Anwendung auf alle Gruppen die Faltenbildungen des Magens neutral nach ihrer Lage benannt wurden. Die Bezeichnungen Gelderds (1909) sind der Tabelle $5 \mathrm{zu}$ entnehmen; im Text sind sie nur für die Fälle erwähnt, die in der Tabelle nicht erfaßt sind. 


\section{Oesophagus}

Der Oesophagus hat eine dorsale, eine ventrale und je zwei laterale Einfaltungen (Abb. 2). Die dorsale Falte wird mit dem Ansteigen des Oesophagus tiefer und endet in einer frei nach innen vorragenden Einstülpung, der Dorsalen Oesophagusklappe ODK. Die laterale Einfaltung ist zweigeteilt: der ventrale und tiefere Teil OLv endet auf der Höhe der Dorsalen Oesophagusklappe, der dorsale und flachere Teil OLd reicht weiter aufwärts und verstreicht in der Cardiawand auf halber Höhe der Vorderränder der großen Lateralplatten CL. Die ventrale Einfaltung ist am oberen Ende in Höhe des Mageneinganges verbreitert und nach hinten umgeschlagen, so daß dadurch ein Querwulst am Anfang des cardiakalen Magenbodens entsteht, der die Ventrale Oesophagusklappe OVK bildet.

Im Zusammenspiel ermöglichen die Wandfalten des Oesophagus einerseits die notwendige Erweiterung bei der Nahrungsaufnahme, andererseits einen wirkungsvollen Abschluß des Magens (Abb. 2, 3).

\section{Cardia}

Wie der Oesophagus zeigt der cardiakale Teil des Magens dorsale, ventrale und laterale Einfaltungen. Das bestimmende Merkmal der vorderen Halbkugel der Cardia ist die unpaare, quer über das ganze Kugeldach verlaufende Falte CFq (Abb. 2), die durch Auf- und Zuspringen eine beträchtliche Lumenerweiterung der Cardia ermöglicht. GELDERD (1909) nennt sie „fold (fl)“. Die Wirkung dieser Querfalte wird noch ergänzt durch ein frontal auf der Cardiakappe senkrecht V-förmig verlaufendes Faltenpaar,

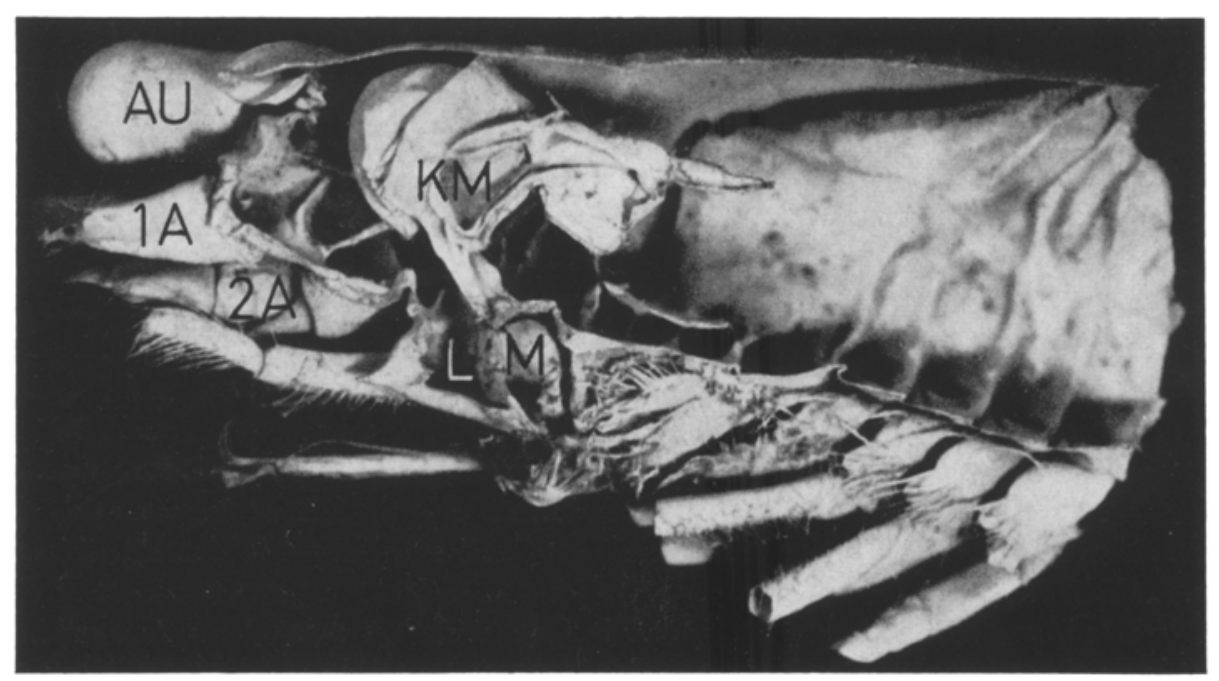

Abb. 1: Lage des Kaumagens im Körper von Neomysis vulgaris. Die linke Körperwand ist entfernt. Kalilaugepräparat, versilbert; Auflichtfoto. 1A, 2A Erste, zweite Antenne; AU Auge; KM Kaumagen; I Labrum; M Mandibel 

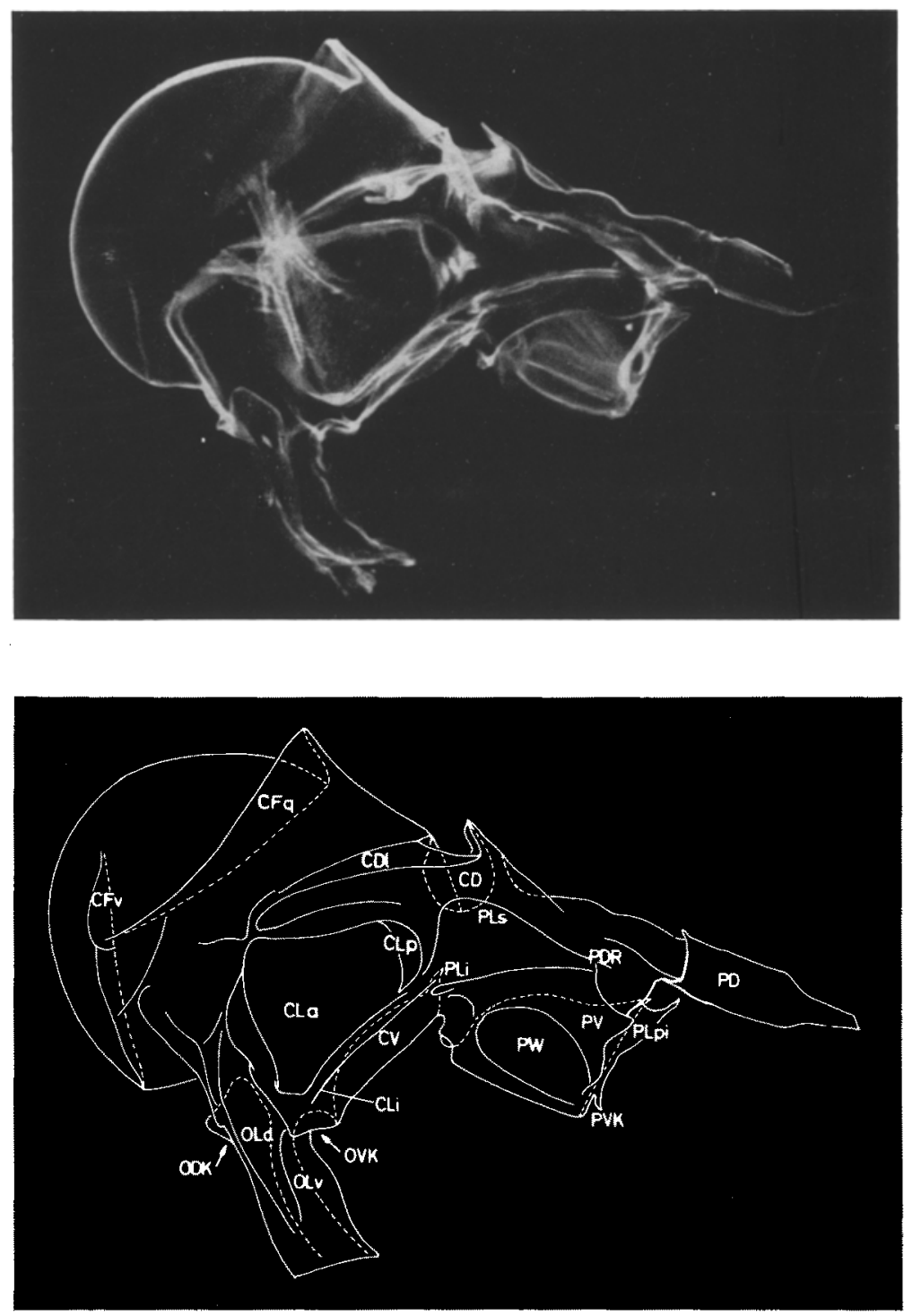

Abb. 2: Seitenansicht des Kaumagens von Neomysis vulgaris. (a) Kalilaugenpräparat; Durchlichtfoto nach Anfärben mit Anilinblau (vgl. Abb. 17a). (b) Ubersicht über die Magenteile. Oesophagus: ODK, OVK Dorsale, Ventrale Oesophagusklappe; OLd, OLv dorsaler, ventraler Teil der Lateralen Oesophagusfalte. Ca rdia : CD Cardiakales Dorsalstiidk; CDl Cardiakales Dorsolaterale; CFq Cardiakale Querfalte, unpaar; CFv Vertikalfalte der Cardia, paarig; CLa vorderer Teil, CLp hinterer Teil des Cardiakalen Laterale; CLi Cardiakales Inferolaterale; CV Cardiakales Ventralstiick. Pylorus: PD Pylorikales Dorsalstïdk; PDR Pylorikale Dorsalrinne; PLi Pylorikales Inferolaterale; PLpi Unteres Endstück der pylorikalen Seitenwand; PLs Pylorikales Superolaterale; PV Pylorikales Ventralstück; PVK Pylorikale Verschlußklappe; PW Pylorikales Wandfilter 


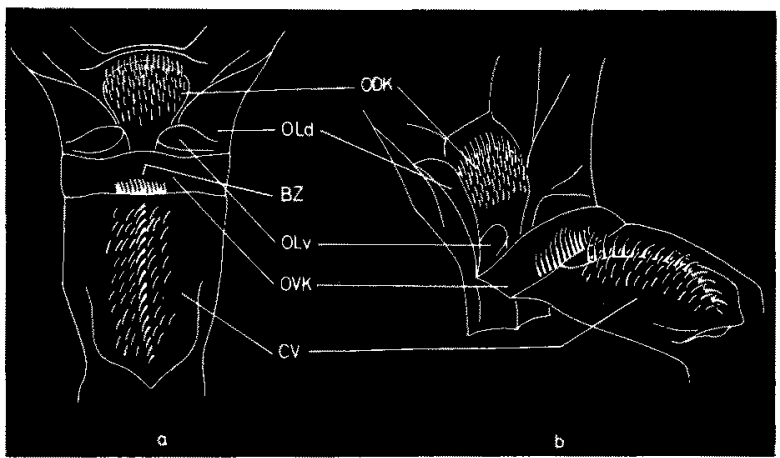

Abb. 3

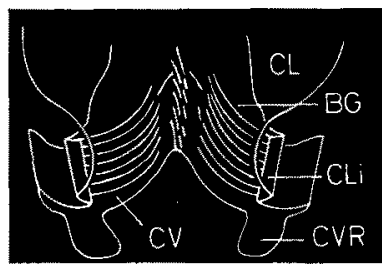

Abb. 4

Abb. 3: Diese Aufsicht auf den Boden der Cardia und den Oesophagus - (a) von dorsal, (b) von dorsocaudal - zeigt die Dorsale Oesophagusklappe ODK, die geteilte Lateralfalte des Oesophagus OLd und OLv, die Ventrale Oesophagusklappe OVK in Form eines Querwulstes, sowie das Cardiakale Ventralstück CV mit dem querstehenden Borstenzaun BZ an der Vorderkante und dem längsgerichteten Borstenbesatz auf dem Kamm

Abb. 4: Querschnitt durch die untere Region der Cardia. Unter dem Cardiakalen Laterale CL trägt das Cardiakale Inferolaterale CLi ein Borstengitter BG, das die Cardiakale Ventralrinne CVR am Fuße des Cardiakalen Ventralstückes CV überdacht

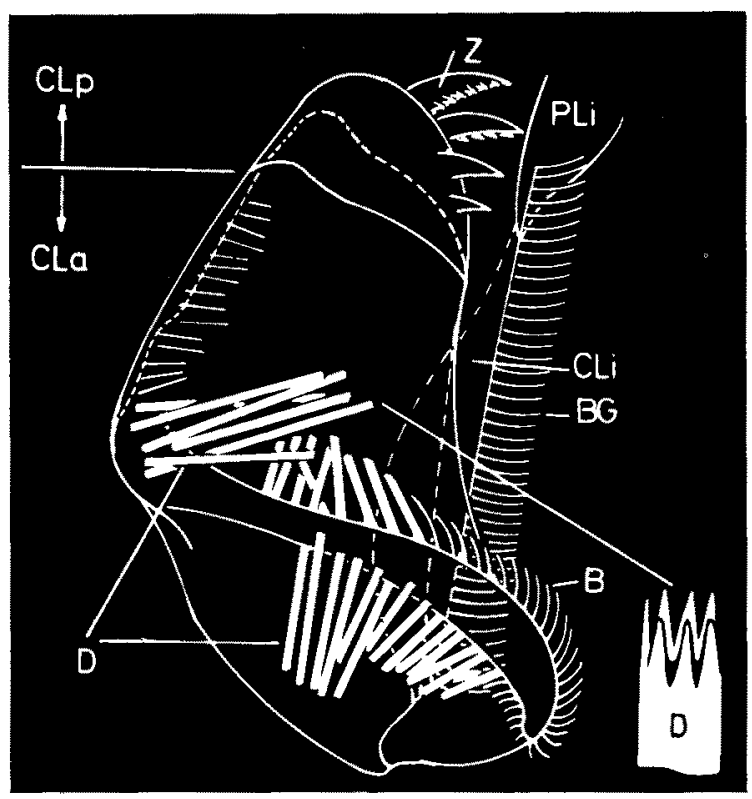

$\Lambda$ bb. 5: Das rechte Cardiakale Laterale CL von vorn. Der vordere Teil CLa trägt auf der ins Magenlumen weit vorspringenden Vorderpartie Borsten $B$, die von unten nach oben länger und stärker werden und dann als steife Dornen D, die in eine Zackenkrone auslaufen, in die Cardia ragen. Der dorsale Rand trägt schwächere Borsten, unter dem ventralen Rand erscheint das Borstengitter BG, das vom Cardiakalen Inferolaterale entspringt und die Cardiakale Ventralrinne iiberdacht. Der hintere Teil CLp ist eine halbmondförmige Einstülpung, die 3 bis 5 Chitinzähne $Z$ trägt, welche abwärts gebogen und ventral gezähnt sind 
die Cardiakalen Vertikalfalten CFv (Abb. 2). Den Boden der Cardia bildet das Cardiakale Ventralstück $C V$, das sich von unten hochwölbt und caudal in einen freien Zipfel ausläuft (Abb. 2-4). Auf der Vorderkante des Cardiakalen Ventralstïckes, also quer zur Magenlängsachse, steht ein Borstenzaun BZ, der Rücken des Cardiakalen Ventralstückes ist mit Borsten besetzt (Abb. 3). Über dem Cardiakalen Ventralstück bildet die Magenwand jederseits eine schmale Falte, die Cardiakalen Inferolateralia CLi, deren

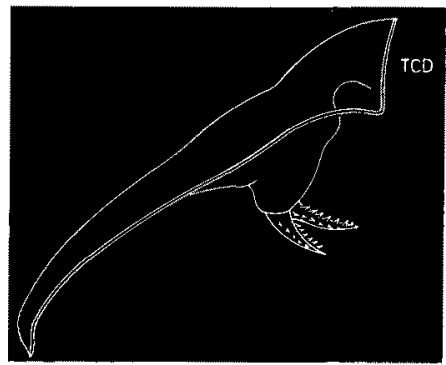

Abb. 6: Das rechte Cardiakale Dorsolaterale CDI von vorn. Es trägt ein Paar starker Chitinzähne, die mit Dornen besetzt sind und zur Medianebene vorragen. TCD bezeichnet die Trennungslinie zum Cardiakalen Dorsalstück (vgl. Abb. 7)

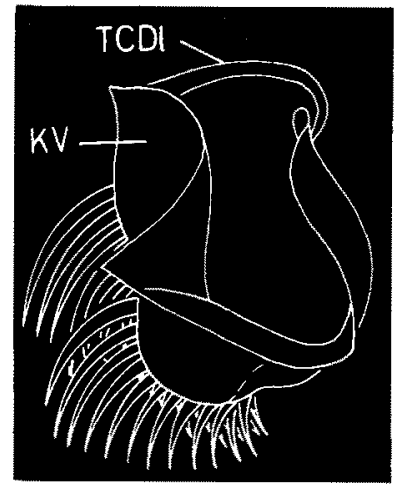

Abb. 7: Das Cardiakale Dorsalstïck CD ist eine tiefe Einstülpung der dorsalen Magenwand. Seine Vorderfläche KV ist konkav, die Ränder tragen starke, rückwärts gekrümmte Borsten. TCDI bezeichnet die Trennungslinie zum Cardiakalen Dorsolaterale (vgl. Abb. 6)

Innenrand ein Borstengitter BG trägt. Dieses ragt einwärts über das Cardiakale Ventralstück und verschließt die Cardiakale Ventralrinne CVR, die der Magenboden beiderseits zwischen Cardiakalem Ventralstück und Seitenwand aufweist (Abb. 4).

Uber den Cardiakalen Inferolateralia nehmen die großen Cardiakalen Lateralia $\mathrm{CL}$ die Flanken der hinteren Cardiahälfte ein. Jedes Laterale zerfällt in einen vorderen Teil CLa und einen hinteren Teil CLp (Abb. 2, 5). Das vordere, in charakteristischer Weise gewölbte Stück ist wie folgt bewehrt: die fast bis zur Mittellinie ins Magenlumen vorspringende Vorderpartie trägt Borsten $B$, die von unten nach oben länger und stärker werden und schließlich als steife Dornen D, die in eine Zackenkrone auslaufen, 
nach vorn und median in die Cardia ragen; die dorsale Kante ist mit einfachen Borsten besetzt. Der hintere Teil des Laterale Clp ist eine halbmondförmige Einstülpung, die eine Reihe von drei bis fünf Chitinzähnen $Z$ trägt, die gedrungener sind als die Zähne des Cardiakalen Dorsolaterale CDl (Abb. 6), abwärts gebogen und ventral mit Dornen versehen sind.

Uber den Lateralia finden sich die Cardiakalen Dorsolateralia CDl (Abb. 6). Sie sind rinnenförmige Einsenkungen mit einem zentralen Säckchen, das von dorsolateral

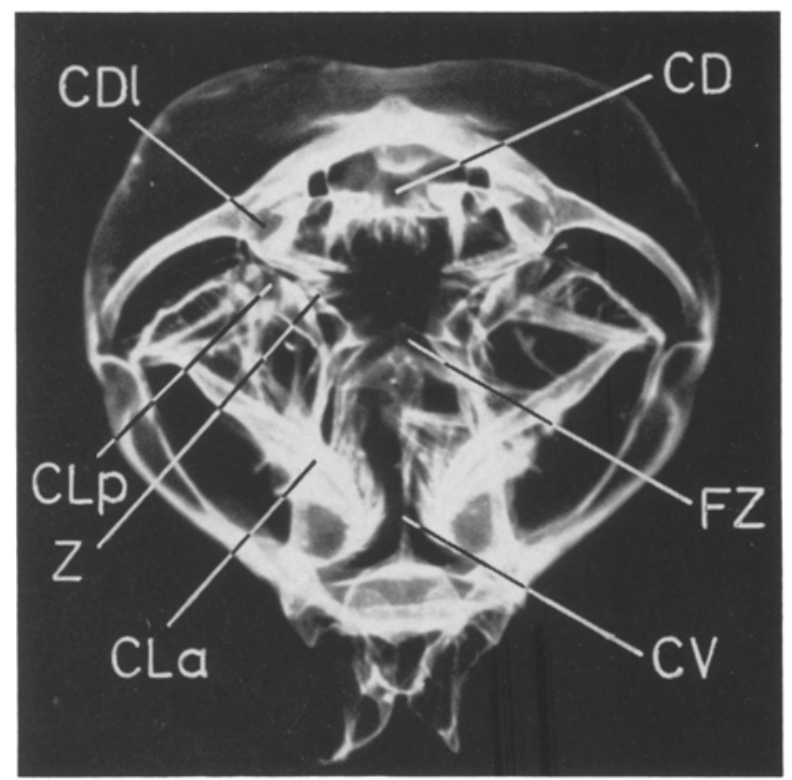

Abb. 8: Einblick in die Cardia von vorn. Die frontale Cardiakappe ist entfernt. Kalilaugepräparat; Durchlichtfoto nach Anfärben mit Anilinblau. - Die großen, V-förmig angeordneten Cardiakalen Lateralia CLa + CLp grenzen ventral an das Cardiakale Ventralstück CV, dorsal an die Cardiakalen Dorsolateralia CDI, die nach hinten zusammenlaufen und jederseits an das Cardiakale Dorsalstück CD anschließen. Der weitgehende Abschluß der Cardia gegen den Pylorus wird bewirkt: dorsal durch die starken Borsten des Cardiakalen Dorsalstiuckes $C D$, lateral durch die Zähne $Z$ der hinteren Abschnitte der Lateralia CLp, ventral durch den freien Zipfel FZ des Cardiakalen Ventralstückes CV

in die Cardia hineinhängt und zwei starke, dorsal gesägte Chitinzähne trägt, die krallenartig zur Medianebene vorragen. GELDERD (1909) nennt sie „eminences with a pair of powerful teeth". Mit ihrem. Hinterrand grenzen die Dosolateralia an das Cardiakale Dorsalstück $C D$, das tief eingestülpt und dicht mit Borsten besetzt ist, die an den Rändern besonders stark und rückwärts gekrümmt sind (Abb. 7).

Das Cardiakale Dorsalstück CD schließt im Zusammenspiel mit einem ventralen und zwei lateralen Partnern, nämlich dem freien Zipfel FZ des Cardiakalen Ventralstückes CV sowie den beiden hinteren Abschnitten der Cardiakalen Lateralia CLp, die Cardia gegen den Pylorus ab (Abb. 8). 


\section{Pylorus}

Wie im Oesophagus und in der Cardia finden sich im pylorikalen Teil des Magens wiederum dorsale, ventrale und laterale Einfaltungen, die in diesem Bereich der Filterung des Nahrungsbreies und der Überführung des unverdaulichen Nahrungsrückstandes in den Mitteldarm dienen. Ventral erhebt sich am Eingang zum Pylorus, noch unter dem frei nach hinten ragenden Zipfel des Cardiakalen Ventralstïckes, das Pylorikale Ventralstück PV, das zum Magenende hin ansteigt und dort wieder steil zum Magenboden abfällt (Abb. 2, 9, 10). Die Flanken des Pylorikalen Ventralstückes PV weisen in der unteren Hälfte je zwei tiefe Pylorikale Filterrinnen PF auf, die von engstehenden Borstengittern verschlossen sind; die Borsten entspringen am unteren Rand

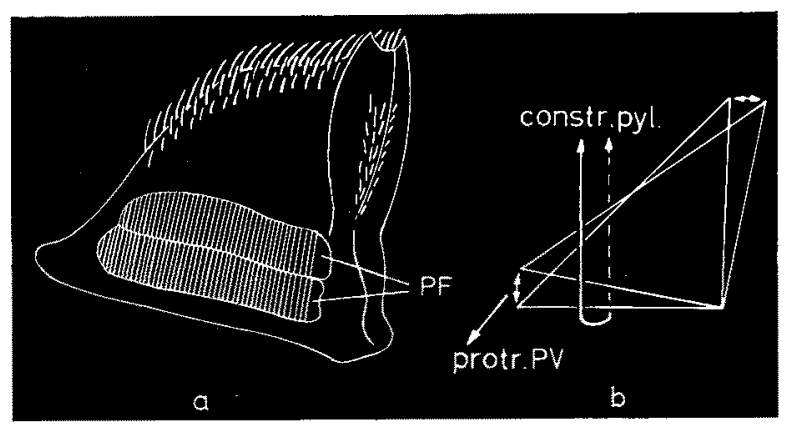

Abb. 9: Das Pylorikale Ventralstück. (a) Der Kamm und die obere Hälfte der Rückwand tragen Borsten, die Flanken je zwei Pylorikale Filterrinnen PF, die durch engstehende Borstengitter verschlossen sind. (b) Schematische Darstellung der Bewegung des Pylorikalen Ventralstückes durch das antagonistisch wirkende Muskelpaar M. protractor des Pylorikalen Ventralstückes (protr. PV) und $M$. constrictor pylori (constr. pyl.)

jeder Rinne und liegen deren oberem Rand an. Wie beim Cardiakalen Ventralstüdk ist der Rücken des Pylorikalen Ventralstückes mit Borsten bestanden. Die obere Kante der Rückwand ist zu zwei seitlichen Spitzen ausgezogen, zwischen denen der durchtretende Borstenkamm eine scheinbare dritte Spitze bildet (Abb. 9). Der untere Rand des Pylorikalen Ventralstïckes PV ist so weich und in sich verschiebbar, daß dieses um die hintere untere Querkante als Drehachse kreisbogenförmig nach vorn-unten bzw. hinten-oben bewegt werden kann, wie der Versuch am mazerierten Magen zeigt. Den Zug nach unten bewirkt eigentlich der M. protractor des Pylorikalen Ventralstuickes (protr. PV) (Abb. 17-19), als Antagonist dient der Constrictormuskel des Pylorus (constr. pyl.) (Abb. 17-19). Dieser Vorgang ist schematisch dargestellt in Abbildung 9b. Dabei verläuft die Außenkante des Pylorikalen Ventralstückes PV (Abb. 9) in einer trichterförmigen Ausbuchtung, die die Seitenwand des Pylorus zwischen Oberem und Unterem Endstück PLps und PLpi aufweist (Abb. 12d).

Eine weitere ventrale Faltenbildung des Pylorus, die bei den meisten Eucarida und Peracarida auftritt (Tab. 4), die Pylorikale Verschlußkappe PVK, ist bei Neomysis offenbar rudimentär und nur als schmaler Chitinsaum ausgebildet (Abb. 2).

Die Seitenwand des Pylorus zeigt folgende Faltenbildungen: Im basalen Bereich 
das Pylorikale Wandflter PW (Abb. 10, 12, 13); daruber das Pylorikale Inferolaterale PLi und über diesem das Pylorikale Superolaterale PLs (Abb. 10, 11), die nach hinten in spitzem Winkel aufeinander zulaufen und wohl als unterer und oberer Rand

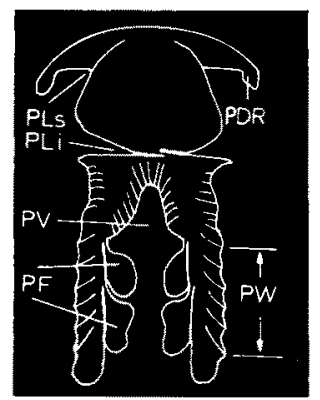

Abb. 10: Querschnitt durch den Pylorus. Die Pylorikalen Inferolateralia PLi können in ihrem vorderen Bereich überlappen und so den Filterteil des Pylorus abdecken. Gegenüber den Pylorikalen Filterrinnen PF ragen die Borsten des Pylorikalen Wandfilters PW als ein vielschichtiges Gitter in den Spalt zwischen Pylorikalem Ventralstück PV und Pyloruswand. Die Pylorikalen Dorsalrinnen PDR sind durch den Borstensaum der Pylorikalen Superolateralia PLs geschützt

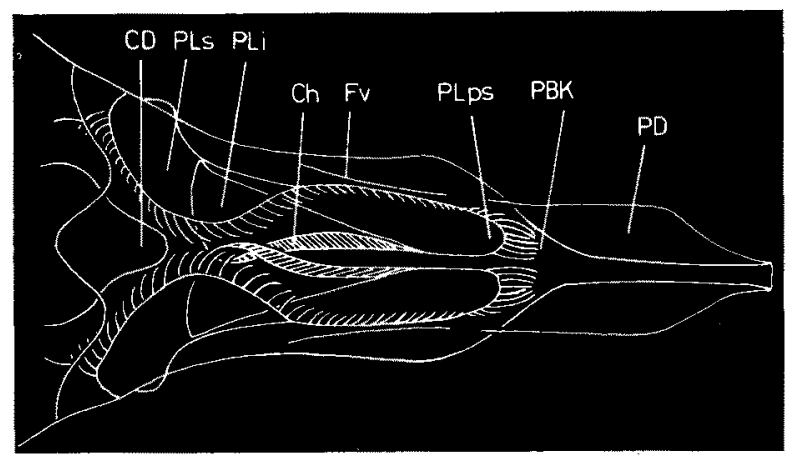

Abb. 11: Aufsicht auf den Pylorus. Als oberste Faltenbildung der pylorikalen Seitenwand entspringen neben dem Cardiakalen Dorsalstück CD die Pylorikalen Superolateralia PLs. Ihr ausgeprägter Borstensaum weist zunächst nach vorn, senkt sich dann nach unten, kehrt hinter dem Cardiakalen Dorsalstïck in die Waagerechte zurïck, um sich, nach dem Verstreichen der Superolateralia in der pylorikalen Seitenwand, in die Senkrechte zu erheben. Die Borsten schließen nun die Dorsalrinnen ab, die hier beginnen, neigen sich darauf nach hinten und inserieren schließlich als Pylorikaler Borstenkorb PBK auf dem Oberen Endstück der pylorikalen Seitenwand PLps. Die Abgrenzung der Dorsalrinne wird verstärkt durch eine vertikale Falte $F^{F}$, die außen neben dem Borstensaum des Superolaterale emporragt. Unter den Superolateralia liegen die Inferolateralia PLi, die im vorderen Teil überlappen können. Sie tragen keine Borsten, sondern einen Chitinsaum CH. Das pylorikale Magendach entsendet nach hinten eine Einfaltung, das Pylorikale Dorsalstück PD, das als unten offenes Rohr weit in den Mitteldarm hineinreicht

einer ursprünglich einheitlichen pylorikalen Lateralfalte zu verstehen sind; im hinteren Bereich der pylorikalen Seitenwand finden sich dann die Oberen Endstücke PLps (Abb. 11-14), die die Verbindung zwischen Infero- und Superolaterale herstellen und 
die dadurch, daß die Inferolateralia PLi tiefer als die Superolateralia PLs eingefaltet sind, waagerecht in den Pylorus ragen; am hinteren Rand schließlich bildet die pylorikale Seitenwand eine füfte Einfaltung, die Unteren Endstücke PLpi (Abb. 12-14).

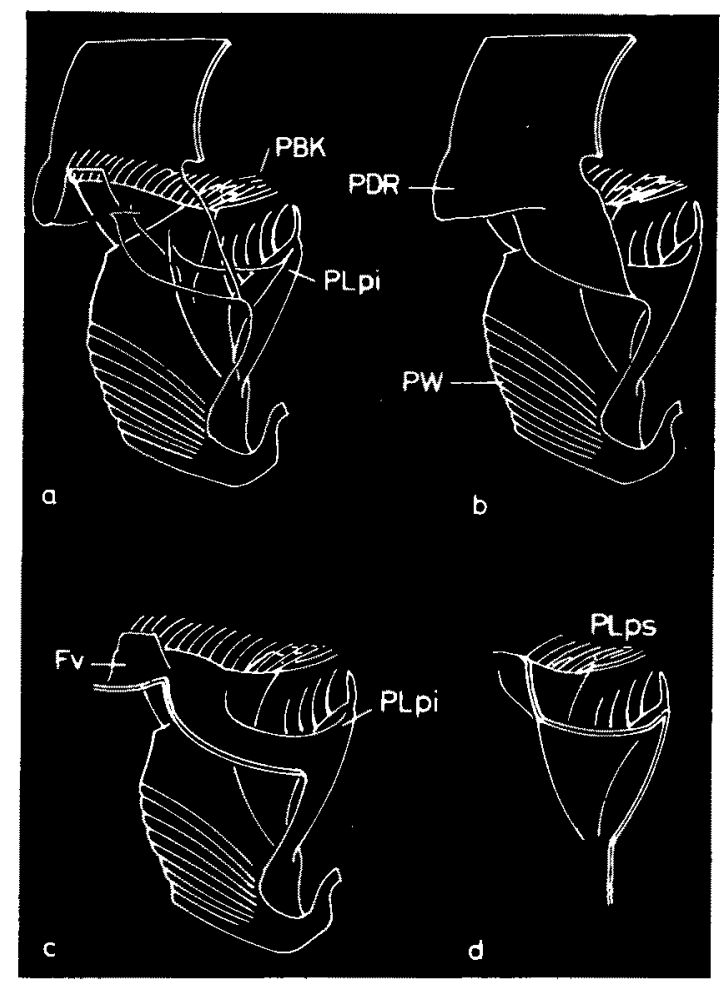

Abb. 12: Der hintere Abschnitt der linken pylorikalen Seitenwand von dorsocaudal. (a) durchsichtig, (b) undurchsichtig gezeichnet. (c) wie (b), aber die Wand der Dorsalen Rinne und das Magendach entfernt. Schnittkante doppelt ausgezogen. (d) Trichterförmige Tasche in der Magenwand zwischen Oberem und Unterem Endstück, in der die Außenkante der Rückwand des Pylorikalen Ventralstückes verläuft (vgl. Abb. 9b). Der äußere Teil des Unteren Endstückes entfernt. Schnittkante doppelt. PLps Oberes Endstück mit PBK (Pylorikalem Borstenkorb); PDR Pylorikale Dorsalrinne; PLpi Unteres Endstück; PW Pylorikales Wandfilter; Fv Vertikalfalte in der Dorsalrinne

Das Pylorikale Wandfilter PW liegt den Pylorikalen Filterrinnen PF des Pylorikalen Ventralstückes PV gegenüber. Es ist ein System von rinnenförmigen Vertiefungen, die flacher sind als die Pylorikalen Filterrinnen und diesen nicht parallel auf der Seitenwand des Pylorus von hinten unten nach vorn oben verlaufen (Abb. 2, 10). Die Borsten der Wandfilterrimnen entspringen nicht am unteren Rand und liegen nicht am oberen Rand an, wie es bei den Borsten der Pylorikalen Filterrinnen der Fall ist, sondern sie entspringen in den Rinnen und ragen schräg aufwärts und verschließen als vielschichtiges Gitter den Spalt zwischen Pylorikalem Ventralstück PV und Seitenwand des Pylorus (Abb. 10). 
Das Pylorikale Inferolaterale PLi stößt beiderseits in Form einer Falte oberhalb des Pylorikalen Ventralstückes medianwärts in den Pylorus vor. Es entspringt in der Verlängerung der Unterkante des Cardiakalen Inferolaterale unter den letzten Borsten, die die Cardiakalen Ventralrinnen abdecken, und über dem freien Zipfel des Cardiakalen Ventralstückes; zunächst ragt es über die Mittellinie hinaus, so daß die Partner überlappen, wird dann schmaler und kehrt über der Kehle im Kamm des

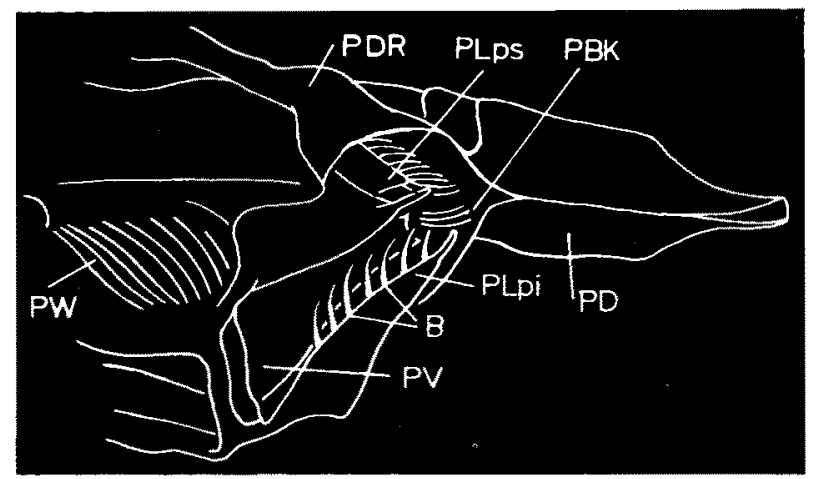

Abb. 13: Caudalansicht des Pylorus von ventrolateral. Das komplizierte Lagegefüge der pylorikalen Seitenwandbildungen besteht aus; der Dorsalen Rinne PDR, dem Oberen Endstück PLps (das den Pylorikalen Borstenkorb PBK trägt), dem Unteren Endstück PLpi (dessen innere Kante eine Borstenreihe B trägt, die gegen die Rückwand des Pylorikalen Ventralstückes PV gerichtet ist und den Spalt zwischen diesem und der Pyloruswand gegen die Mitteldarmdrüsen abschließt) und dem Pylorikalen Wandfilter PW

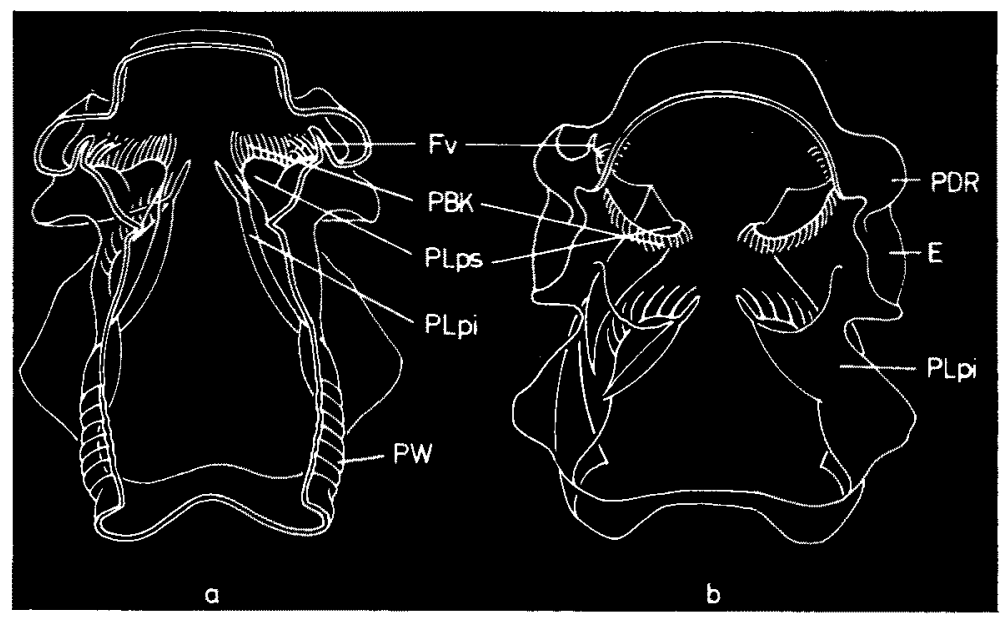

Abb. 14: Endabschnitt des Pylorus, (a) von vorn, (b) von dorsocaudal. Die linke Hälfte ist jeweils durchsichtig, die rechte undurchsichtig gezeichnet. Schnittkanten doppelt ausgezogen. Fy Vertikalfalte, die in die Dorsalrinne hineinragt; E Erweiterter Endabschnitt der Dorsalrinne; PBK Pylorikaler Borstenkorb; PDR Pylorikale Dorsalrinne; PLpi, PLps Unteres, Oberes Endstück der pylorikalen Seitenwand; PW Pylorikales Wandfilter 
Pylorikalen Ventralstüickes in die Seitenwand zurück. Der Saum der Pylorikalen Inferolateralia besteht nicht aus Borsten, sondern er ist ein Chitinsaum, der dadurch entsteht, daß sich obere und untere Faltenwand im terminalen Bereich aufeinanderlegen (Abb. 5, 10, 11).

Die Pylorikalen Superolateralia PLs entspringen über den Pylorikalen Inferolateralia PLi, sie sind voluminöser als jene und überlappen nicht. Mit dem oberen Abschnitt der pylorikalen Seitenwand, die nach außen überhängt, bilden sie die Pylorikalen Dorsalrinnen PDR, die nach innen durch den Borstensaum der Pylorikalen Superolaterialia und eine kleine Vertikalfalte $F_{V}$ abgeschlossen werden, die außen neben den Borsten jederseits senkrecht in die Dorsalrinne ragt (Abb. 10-12). Der Borstensaum, der den Pylorikalen Superolateralia aufsitzt (Abb. 11), weist zunächst nach vorn, dann, den starken Randborsten des Cardiakalen Dorsalstückes ausweichend, nach unten; unter der napfförmigen Mulde, die die Dorsalwand des Pylorus hinter dem Cardiakalen Dorsalstuick aufweist, kehrt der Borstensaum in die Waagerechte zurück, um sich dann in die Senkrechte zu erheben. Nach dem Verstreichen der Superolateralia in der pylorikalen Seitenwand neigen sich die Borsten in zunehmendem Maße nach hinten und inserieren schließlich terminal auf einem Zipfel, dem Oberen Endstück PLps, das Supero- und Inferolaterale verbindet. Von den Rändern der Oberen Endstïcke ragen die Borsten wie die Finger zweier hohler Hände als Pylorikaler Borstenkorb PBK nach hinten in den Mitteldarm hinein (Abb. 11-14).

Die Unteren Endstücke PLpi sind Einfaltungen, die die pylorikale Seitenwand unterhalb der Oberen Endstücke PLps nach oben-innen erfährt (Abb. 12-14); sie sind

Tabelle 1

Magenstücke bei Neomysis vulgaris

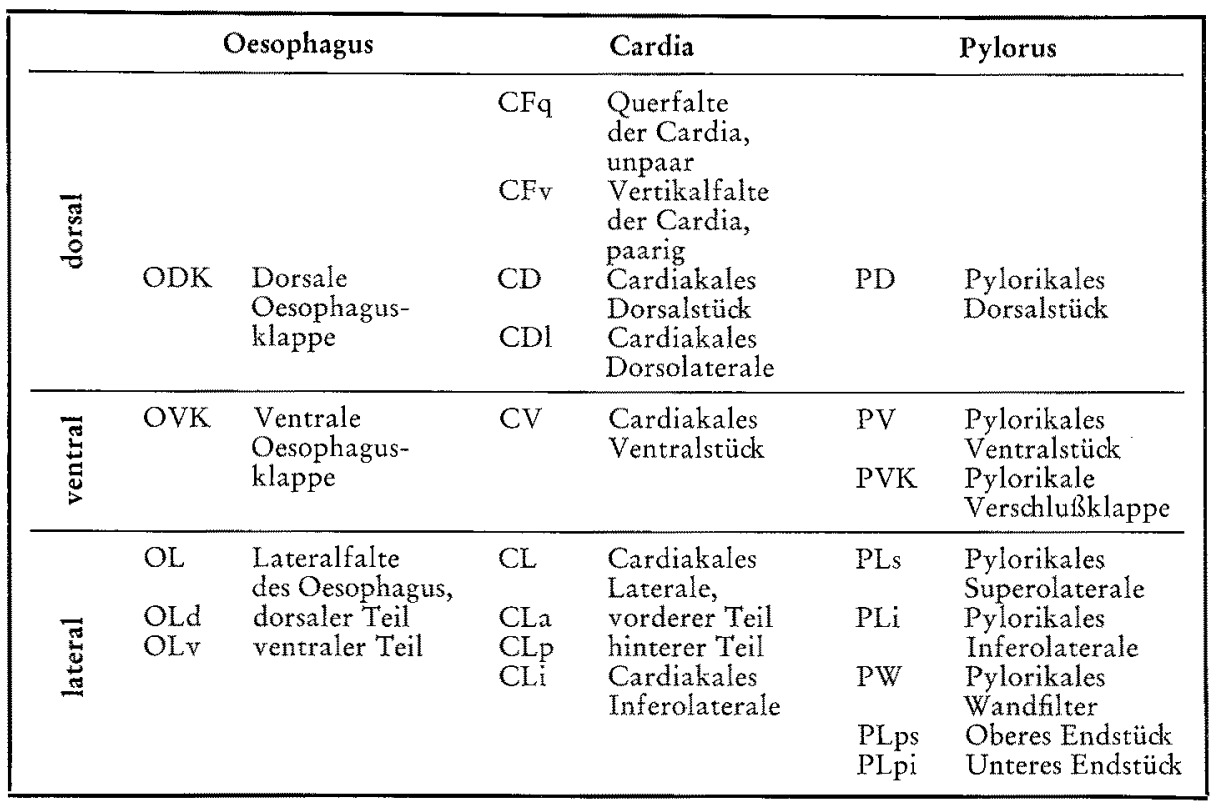


aufwärts in eine Spitze ausgezogen und ergeben jederseits eine Klappe, die in der Caudalansicht wie die zurückgeschlagenen Hältten eines Zelteinganges wirken. Am inneren Umschlagrand dieser Klappen steht eine Reihe langer Dornen, die auf- und einwärts gegen die Außenkante des Pylorikalen Ventralstückes gerichtet sind; sie verschließen gitterartig den Spalt $z$ wischen Pyloruswand und Pylorikalem Ventralstïck.

Schließlich schickt das Pylorusdach noch eine Einfaltung nach hinten in den Mitteldarm hinein, die ein unten offenes Rohr bildet. Dieses Pylorikale Dorsalstück PD bildet zusammen mit dem Pylorikalen Borstenkorb und den Zipfeln des Unteren Endstückes den Pylorikalen Trichter (Abb. 2, 13, 17-19).

Zusammenfassend zeigt Tabelle 1 eine Aufstellung der Stücke, die am Kaumagen von Neomysis ausgebildet sind.

\section{Die Muskulatur des Labrum und Magens}

Der Funktion des Kaumagens dient eine umfangreiche Muskulatur (Abb. 15-19; Tab. 2). Entsprechend den Verhältnissen bei den Dekapoden sind zwei Gruppen von Muskeln zu unterscheiden: die Muskeln, die am Exoskelett oder am Endoskelett ("Sehne" des Mandibelmuskels) entspringen und von außen an den Magen herantreten, und solche, die von einem Magenteil zum anderen verlaufen und sie miteinander verbinden.

Der Umstand, daß einige Muskeln des Oesophagus in der Oberlippe entspringen, führte zu einer Darstellung der gesamten Muskulatur des Labrum, die hier der folgenden Beschreibung der eigentlichen Magenmuskulatur vorangestellt sei.

\section{Die Muskulatur des Labrum}

Die deutlich vom Körper abgesetzte, voluminöse Oberlippe von Neomysis wulgaris, die cranial in eine Spitze ausgezogen ist (Abb. 1), wird von einem System von Muskeln durchzogen, die besonders die relativ dünn chitinisierte Rückwand befähigt, durch plastische Formveränderung den Kau- und Freßakt zu unterstützen. Zu unterscheiden sind neun paarige und ein unpaarer Muskel (Abb. 15).

(1) Musculus protactor $I$ der Rückwand des Labrum (L I), paarig. Die Muskeln entspringen an der vorderen oberen Seitenwand des Labrum, ziehen leicht konvergierend rückwärts und greifen an der Rückwand der Oberlippe beiderseits dicht unter der Mundöffinung an.

(2) M. protactor II der Rückwand des Labrum (L II), paarig. Die Partner dieses wohl eigentlich paarigen Muskelzuges entspringen auf der ventralen Mittellinie der Oberlippe, ziehen als mehr oder weniger einheitlicher Strang schräg aufwärts nach hinten und greifen auf halber Höhe der Rückwand des Labrum an, unterhalb des dort gelegenen Borstenfeldes.

(3) M. protractor III der Rückwand des Labrum (L III), paarig. Die beiden Muskelzüge entspringen unterhalb und vor $L I$, verlaufen leicht konvergierend abwärts und greifen beiderseits dicht über der unteren Kante der Oberlippe an, die ein Borstenvolster bildet. 
(4) M. protractor IV der Rückwand des Labrum (L IV), paarig. Diese Muskeln entspringen dicht neben der Mittellinie im Einschnitt auf halber Höhe der vorderen Oberlippenwand, verlaufen zunächst parallel nach hinten, um dann plötzlich zu divergieren. Sie weichen L II aus, verlaufen dann aber wieder fast parallel nach hinten und greifen zwischen L II und L III an der Rückwand des Labrum an.

(5) $M$. protractor $V$ der Rückwand des Labrum (L V), paarig. Die beiden Partner entspringen am Boden der Oberlippe, verlaufen konvergierend nach hinten oben und greifen außen über L I unterhalb der Mundöffnung an.

(6) $M$. protractor VI der Rückwand des Labrum (L VI), paarig. Das Muskelpaar entspringt dicht außen vor $\mathrm{L} V$, verläuft ebenfalls konvergierend, aber etwas flacher ansteigend nach hinten und greift außen unter $L V$ an der Rückw and der Oberlippe an.

(7) M. protractor VII der Rückwand des Labrum (L VII), paarig. Die beiden Muskeln entspringen im hinteren äußeren Bodenbereich der Oberlippe, verlaufen stark konvergierend aufwärts zur Rückwand des Labrum und greifen unterhalb L II dort an.

(8) M. protractor VIII der Rückwand des Labrum (L VIII), paarig. Das Muskelpaar entspringt noch etwas weiter außen und hinten als L VII, verläuft ebenfalls konvergierend einwärts und nach oben und greift auf gleicher Höhe wie L VII, jedoch außerhalb dieses Muskels, an der Rückwand der Oberlippe an.

(9) M. contractor des Labrum (L IX), paarig. Diese beiden starken Muskeln ziehen vom zentralen Bereich der Bodenplatte der Oberlippe parallel zur Mittellinie vorwärts aufwärts zur vorderen Wand des Labrum.

(10) M. transversus des Labrum (L X), unpaar. Der Quermuskel durchläuft die Oberlippe oberhalb L II, L III sowie L IV und unterhalb L I, L V und L VI.

Die übrigen in der Abbildung 15 noch verzeichneten Muskeln sind Dilatatoren des Oesophagus, die erst bei der Beschreibung der Magenmuskulatur berücksichtigt werden.

Bei der Benennung der Oberlippenmuskulatur habe ich mich nicht auf die Verlaufsrichtung der Muskeln im Verhältnis zur Längsachse des Tieres bezogen, sondern - soweit möglich - auf die Rückwand des Labrum, um eine Grundlage zu haben für den Vergleich der Muskeln in verschiedenen systematischen Gruppen. Das ist nicht möglich bei einer Bezugnahme auf die Längsachse des Tieres, denn am Vergleich von Mysidaceen und Cumaceen kann gezeigt werden, daß einander entsprechende Muskeln in beiden Gruppen in verschiedener Richtung verlaufen, da der Oesophagus und damit die Rückwand des Labrum, an der die Muskeln angreifen, bei den Mysidaceen schräg nach vorn oben, bei den Cumaceen dagegen schräg nach hinten oben weist. Longitudinalmuskeln der einen Gruppe sind also zum Beispiel Dorsoventralmuskeln bei der anderen Gruppe. Ein Vergleich der Muskeln müßte unter diesen Voraussetzungen zu einer paradoxen Bezeichnungsweise und zu Mißverständnissen führen. Die Bezugnahme auf die Rückwand der Oberlippe bei der Benennung der Muskeln vermeidet solche Schwierigkeiten.

Die Funktion der beschriebenen Oberlippenmuskeln wird einerseits in der örtlichen Formveränderung vor allem der Oberlippenrïckstand liegen, die in mannigfacher Weise durch das Zusammenspiel der verschiedenen Muskeln möglich ist. Die direkte Bewegung der Borstenpolster auf der Unterkante und auf halber Höhe der Rückwand des Labrum wird entsprechend den Verhältnissen bei Hemimysis (MANToN 
1927) durch je ein Muskelpaar bewirkt, nämlich durch den M. protractor III (L III) (Abb. 15) - nach MANTON "a pair of longitudinal muscles, which pass to the anterior labral ectoderm" - und M. protractor II (L II) (Abb. 15) - nach Manton "the median antero-posterior muscle". Dabei kann die Bewegung durch die Kombinationsmöglichkeiten von Kontraktion und Erschlaffung der verschiedenen Partner sicher wirkungsvoll variiert werden.

Andererseits scheint die Oberlippe entsprechend den bei Cumaceen geschilderten Verhältnissen (OELZE 1931; SIEWING 1952) eine propulsatorische Funktion zu haben, die bei Kontraktion des Transversalmuskels ( $\mathrm{L} \mathrm{X}$ ) und des $M$. contractor ( $\mathrm{L}$ IX) (Abb. 15) sehr wirksam sein müßte.

\section{Vergleich mit der Oberlippe von Diastylis ratbkei}

Was die Lage der Muskeln bei Mysidaceen einerseits und Cumaceen andererseits angeht, lassen sich auffallende Übereinstimmungen feststellen, wenn man sie an der Richtung des Oesophagus beziehungsweise davon ausgehend an der Rückwand der Oberlippe orientiert (vgl. Abb. 15 u. 16). Der Muskel $f$ beziehungsweise g (OELzE) entspricht L IX beziehungsweise L III, wenn man ihren Verlauf vergleicht: die relative Lage beider zueinander stimmt überein; $g$ ist schwächer als $f$, ebenso wie L III gegenüber L IX; die Partner von $f$ beziehungsweise L IX konvergieren nicht, während die von $\mathrm{g}$ beziehungsweise L III leicht zusammenlaufen.

Weiterhin muß wohl der Muskel k (OELZE) dem L Il entsprechen, denn wenn k auch nicht als mehr oder weniger unpaarer Strang wie L II auf der Mittellinie verläuft, sondern ausgesprochen paarig ist, so ist doch seine relative Lage zu $f$ und g entsprechend der von L II zu L IX und L III: L II beziehungsweise $k$ entspringt vor L IX beziehungsweise f; $L$ II beziehungsweise $k$ verläuft als inneres Paar $z$ wischen $L$ IX und L III beziehungsweise $f$ und $g$.

Nicht so auffällig ist die Übereinstimmung des Muskels h (OELzE) mit L V und L VI, jedoch spricht auch in diesem Fall einiges für eine Entsprechung; laut Beschreibung von OELZE ist h teilweise in zwei Stränge gespalten, könnte also durch Vereinigung von $L V$ und $L$ VI entstanden beziehungsweise könnten $L V$ und $L V I$ aus $h$ hervorgegangen sein; $h$ liegt außerhalb von $f$ und $g$, wie $L V$ und $L V I$ außerhalb von L IX und L III verlaufen; sowohl $h$ als auch $L V$ und $L$ VI ziehen leicht konvergierend zur Rückwand des Labrum. Wichtige Hinweise zu diesen Fragen könnte eine Untersuchung der Verhältnisse bei den Lophogastriden, der gemeinsamen Basisgruppe von Mysideen und Cumaceen, bringen.

Deutlicher wiederum scheint mir die Öbereinstimmung von b (OELZE) und $\mathrm{L} I \mathrm{zu}$ sein, wenn auch die Partner von L I im Gegensatz zu b konvergierend verlaufen; denn $b$ entspringt oberhalb $f$ und $g$ wie L I oberhalb von L III und L IX, und sowohl $b$ als auch $L \mathrm{I}$ finden sich an der oberen Grenze der Oberlippe. Dazu kommt folgendes: Wie der Muskel a bei Diastylis (Oelze 1931), so überbrückt M. dil. oe. 1. III bei Neomysis die Rinne zwischen seitlicher Körperwand und Oesophagus und greift, wie a neben $b$, an der Seitenwand des Oesophagus an, neben der Insertion von $L$ I an der Oberlippenrückwand. M. dil. oe. 1. III wie a können als Antagonisten der Oberlippen- 


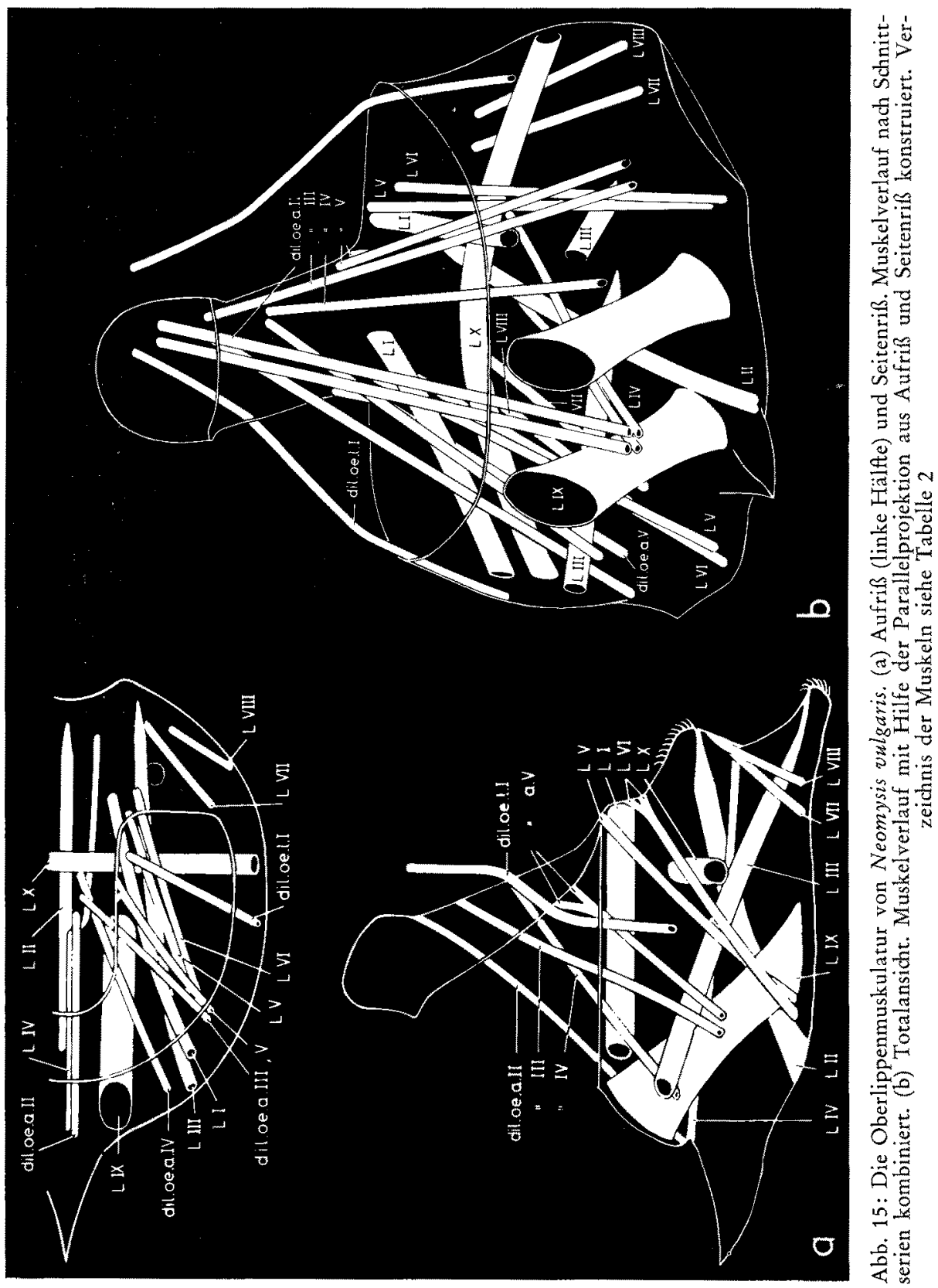


muskulatur bei der propulsatorischen Funktion des Labrum dienen. Von den verbleibenden Muskeln c, d, e, i und t (Oelze) sowie L VII, VIII, IV und X erlauben nur noch $t$ und L X einen Vergleich. $t$ liegt zu $f$, g und $k$ wie L X zu L III, IX und II; einschränkend ist jedoch zu bemerken, daß L V und VI über L X verlaufen, während $t$ oberhalb h die Oberlippe durchzieht.

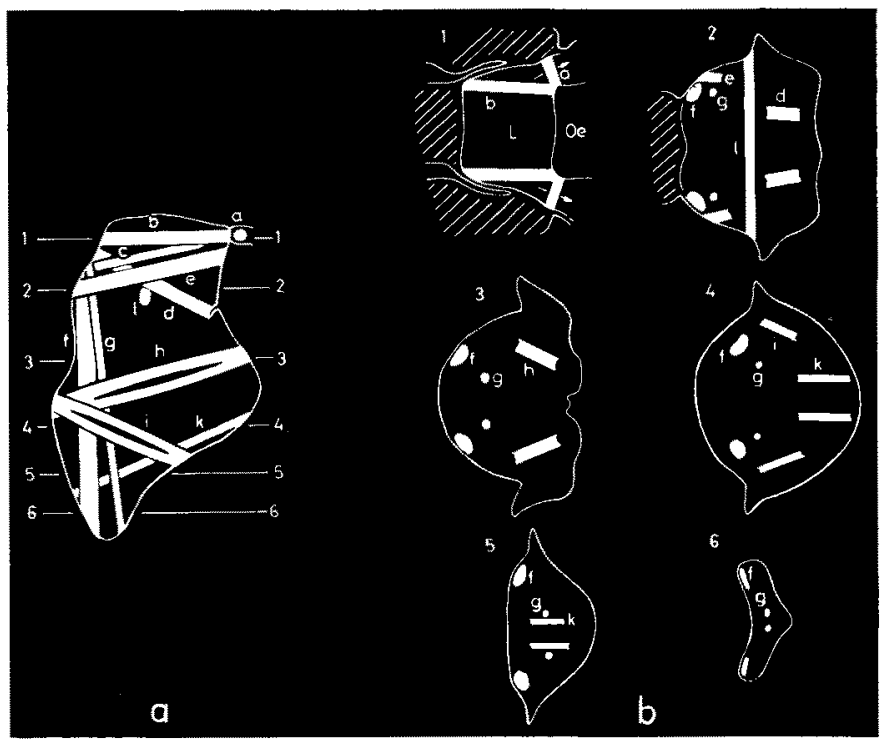

Abb. 16: Die Oberlippenmuskulatur von Diastylis ratbkei. (a) Vertikalschnitt durch die Oberlippe mit ihren quer- und längsverlaufenden Muskelzügen. (b) Horizontalschnitte durch die Oberlippe in Höhe der punktierten Linien in (a). L Labrum, Oe Oesophagus. (Nach OfLze (1931), [a] umgezeichnet)

Zusammenfassend ist zu sagen, daß mehrere Muskeln in der Oberlippe von Neomysis und Diastylis das Homologiekriterium der Lagegleichheit erfüllen und so für eine Homologie der Oberlippenmuskulatur bei Mysidaceen und Cumaceen sprechen. Eine Bestätigung dieser Annahme ist jedoch nur durch entsprechende Untersuchungen an weiteren Gruppen, besonders der Basisgruppe der Lophogastriden, zu erbringen.

Die Angaben über die Oberlippenmuskulatur der Dekapoden zum Vergleich heranzuziehen, erscheint mir verfrüht, solange nicht Beobachtungen außer an Lophogastriden besonders an primitiveren Dekapodengruppen die Angaben Ringels (1924) ergänzen.

\section{Die Muskulatur des Oesophagus}

(1) M. dilatator oesophagi anterior I (dil. oe. a. I), paarig (Abb, 17-19). Der Muskel entspringt an der Mittellinie in einer medianen Mulde der ventralen Körperwand zwischen den Einmündungen der zweiten Antennen, in der auch der dil.car. a.III 
seinen Anfang nimmt. Er zieht mit diesem zusammen nach hinten aufwärts bis unter den tiefsten Punkt der Cardia, biegt dann ab in die Horizontale und greift am vorspringenden oberen Rand der Dorsalen Oesophagusklappe ODK an.

(2) $M$. dilatator oesophagi anterior II (dil. oe. a. II), paarig (Abb. 15, 17-19). Der Muskel entspringt auf halber Höhe der vorderen Wand des Labrum direkt über dem Muskel L IV, zieht aufwärts nach hinten, durchstößt die Ringmuskulatur des Oesophagus und greift in der dorsalen Oesophagusfalte an, fast auf gleicher Höhe mit dem M.dil.oe. a.I.

(3) M. dilatator oesophagi anterior III (dil. oe. a. III), paarig (Abb. 15, 17-19). Der Muskel entspringt an der äußeren Wand der Oberlippe vor dil. oe. a. V, kreuzt über dil. oe. a. IV nach innen, durchstößt den Ringmuskel des Oesophagus und greift unterhalb dil. oe. a. II in der dorsalen Oesophagusfalte an.

(4) M. dilatator oesophagi anterior IV (dil. oe. a. IV), paarig (Abb. 15, 17-19). Der Muskel entspringt an der vorderen Wand des Labrum zwischen L IX und L III, zieht weniger stark einwärts und weniger steil aufwärts als dil. oe. a. III, kreuzt unter diesem durch, durchstößt den Ringmuskel des Oesophagus und greift unterhalb von dil. oe. a. III in der dorsalen Oesophagusfalte an.

(5) M. dilatator oesophagi anterior V (dil. oe. a. V), paarig (Abb. 15). Der Muskel entspringt dicht hinter dil. oe, a. IV an der seitlichen Wand der Oberlippe, steigt einwärts gewendet flacher als dieser nach hinten an, spaltet im letzten Abschnitt in zwei Bündel auf, die dann untereinander an der vorderen Außenkante des Oesophagus nur wenig über der Mundöffnung angreifen.

(6) M. dilatator oesopbagi lateralis I (dil. oe. 1. I), paarig (Abb. 15, 17-19). Dieser Muskel entspringt ebenfalls im Labrum, an der oberen Seitenwand vor und über dem Ansatz des Transversalmuskels L X. Er steigt senkrecht aufwärts, biegt nach dem Austritt aus der Oberlippe in das Körperinnere nach hinten und einwärts, dabei flacher ansteigend, durchstößt dann etwa auf halber Höhe der lateralen Oesophaguswand die Ringmuskulatur, um zwischen dieser und der Wand des Oesophagus wieder senkrecht anzusteigen und greift schließlich in der ventralen und tieferen Einfaltung OLv (Abb. 2) der seitlichen Oesophaguswand an.

(7) M. dilatator oesophagi lateralis $I I$ (dil. oe. 1. II), paarig (Abb. 17-19). Der Muskel entspringt zusammen mit $\operatorname{dem} M$. dilatator oesophagi lateralis $I I I$ am seitlichen Integument oberhalb des Oberlippenrandes, steigt nach hinten gewendet an, durchstößt die Ringmuskelschicht des Oesophagus und greift etwa auf Höhe des dil. oe. a. IV im dorsalen und flacheren Teil der lateralen Oesophaguseinfaltung OLd (Abb. 2) an.

(8) M. dilatator oesophagi lateralis III (dil. oe. 1. III), paarig (Abb. 17-19). Der Muskel entspringt zusammen mit $M$. dilatator oesophagi lateralis $I I$ am seitlichen Integument, verläuft horizontal nach innen, etwas stärker rückwärts gewendet als dieser, zum Oesophagus, durchstößt den Ringmuskel und greift im ventralen Teil der lateralen Einfaltung des Oesophagus OLv (Abb. 2) an.

Der $M$. dilatator oesophagi lateralis $I I I$ entspricht seiner Lage nach sehr gut dem von Oelze (1931) an Diastylis beschriebenen Muskel a an der oberen Grenze des Labrum (Abb. 16), der den Raum zwischen Oesophagus und Körperwand überbrückt 
und die propulsatorische Funktion der Oberlippe unterstützt. Bei Neomysis scheinen die Verhältnisse ähnlich zu liegen.

(9) M. dilatator oesophagi posterior I (dil. oe. p. I), paarig (Abb. 17-19). Der Muskel entspringt am Endoskelett (Sehne des Mandibularmuskels), verläuft etwa horizontal einwärts und greift am oberen Rande der hinteren Oesophaguswand an, ehe diese nach hinten umbiegt, um den Querwulst OVK vor dem Cardiakalen Ventralstück CV (Abb. 2) zu bilden.

(10) M. dilatator oesophagi posterior II (dil. oe. p. II), paarig (Abb. 17-19) und

(11) $M$. dilatator oesophagi posterior III (dil. oe. p. III), paarig (Abb. 17-19), entspringen untereinander aus dem Levator des Mandibelmuskels, der auf der Höhe der Grenze Cardia/Pylorus senkrecht zum dorsalen Integument zieht. Sie entspringen etwa auf dem Niveau der pylorikalen Seitenstücke, verlaufen abwärts und einwärts, passieren innerhalb des $M$. dilatator oesophagi posterior $I$ und greifen an der Außenkante der rückwärtigen Oesophaguswand an, und zwar der $M$. dilatator oesophagi posterior II an dem Vorsprung etwa auf halber Höhe des Oesophagus, der M. dilatator oesophagi posterior III über der Mundöffnung.

(12) M. constrictor oesophagi (constr. oe.) (Abb. 19). Dieses Muskelband, das den Oesophagus umgibt und als Antagonist der Dilatatoren wirkt, die jeweils durch ihn hindurchtreten, besteht nicht nur aus parallelen Ringmuskelbündeln. Auf der vorderen Wand des Oesophagus verläuft ein senkrechter Muskelzug, der dadurch entsteht, daß Teile besonders der obersten und untersten Ringmuskeln nach Passieren der lateralen Oesophaguswand mehr oder weniger in die schräge oder senkrechte Richtung abbiegen, seitlich an den frontalen Dilatatoren des Oesophagus vorbei - oder zwischen ihnen hindurchlaufen und schließlich wieder in anderen Ringmuskelbündeln aufgehen. Dieses Geflecht aus horizontal, senkrecht und diagonal verlaufenden Muskelzügen auf der vorderen Wand des Oesophagus endet am Fuße des Oesophagus in einem Zipfel, der an der Rückwand des Labrum ansetzt. Der senkrechte Muskelzug setzt sich am oberen Ende des Oesophagus höher als die Ringmuskelschicht fort, tritt zwischen den beiden Partnern des $M$. dilatator oesopbagi anterior $I$ hindurch und geht in dem einzelnen Ringmuskelzug auf, der sich an den Vorderkanten der seitlichen Oesophaguswände vom Hauptmuskel gelöst hat und hier über dem oberen Rand der Dorsalen Oesophagusklappe entlangzieht (Abb. 19).

\section{Die Muskulatur der Cardia}

(13) Musculus dilatator cardiae anterior I (dil. car. a. I), paarig (Abb. 17-19). Der Muskel entspringt beiderseits der Mittellinie an der Stirnwand von Neomysis, dicht unterhalb der rostrum-artigen Falte, zieht leicht auswärts und ansteigend nach hinten und greift auf der kugelförmigen Kappe der Cardia an.

(14) M. dilatator cardiae anterior II (dil. car. a. II), paarig (Abb. 17-19). Die beiden Partner dieses Muskels entspringen unterhalb des $M$. dilatator cardiae anterior I an der Stirnwand des Tieres, ziehen leicht divergierend abwärts nach hinten und greifen am vordersten Punkt der Cardiakappe dicht neben der Mittellinie an.

(15) $M$. dilatator cardiae anterior III (dil. car. a. III), paarig (Abb. 17-19). Die 
beiden starken Partner entspringen an der Mittellinie in einer medianen Mulde der ventralen Körperwand zwischen den Einlenkungen der zweiten Antennen, wo auch $\operatorname{der} M$. dilatator oesophagi anterior I seinen Anfang nimmt. Sie ziehen parallel, über dem genannten Muskel liegend, nach hinten aufwärts, im letzten Abschnitt, nachdem der Oesophagusdilatator in die Horizontale abgebogen ist, unter der Cardiawand entlang, die hier eine tiefe Kehle mit dem Oesophagus bildet. Im tiefsten Punkt dieser Kehle oberhalb der Dorsalen Oesophagusklappe greifen sie an der Cardiawand an.

(16) M. dilatator cardiae lateroanterior (dil. car. la.), paarig (Abb. 17-19). Der kurze Muskel entspringt an der vorderen Körperwand, verläuft einwärts und ein wenig aufwärts und greift an dem Vorsprung an, den die äußeren Wände des auf der Cardiakappe senkrecht verlaufenden Faltenpaares $\mathrm{CFv}$ auf halber Höhe aufweisen.

(17) M. dilatator cardiae lateralis I (dil. car. 1. I), paarig (Abb. 17-19). Der Muskel entspringt mit hochovaler Ansatzfläche an der lateralen Körperwand vor der Vorwölbung des Mandibelmuskels, zieht fast senkrecht zur Körperachse, nur leicht rückwärts und aufwärts gewendet, ins Körperinnere und greift, da die unteren Stränge des Muskels stärker ansteigen als die oberen und so neben diese treten, mit querovaler Ansatzfläche an der unteren Ecke der Cardiakalen Seitenplatten an.

(18) M. dilatator cardiae lateralis II (dil. car. 1. II), paarig (Abb. 17-19). Der Muskel entspringt ebenfalls an der lateralen Körperwand, hinter und unterhalb des $M$. dilatator cardiae lateralis $I$, zieht parallel mit diesem aufwärts und einwärts und greift am untersten Punkt der cardiakalen Seitenwand an, über der Linie, in der die Oesophagusrückwand und das Cardiakale Ventralstïck zusammenstoßen.

(19) $M$. dilatator cardiae inferior (dil. car. i.), paarig (Abb. 17-19). Der Muskel entspringt auf der Sehne des Mandibelmuskels unweit der Mittellinie, zicht aufwärts und vorwärts, die beiden Partner divergieren leicht und schließen den Protraktormuskel des Pylorikalen Ventralstüickes PV ein, bleiben innerhalb von $M$. dilatator oesophagi posterior $I l$ und $I I I$, durchstoßen den $M$. constrictor cardiae und greifen an den Außenkanten des Cardiabodens an.

(20) M. retractor cardiae (retr. car.) (Abb. 17-19) entspringt als doppeltes Muskelpaar auf dem unteren Teil der frontalen Cardiakappe. Es verläuft divergierend abwärts über den unteren Abschnitt der senkrechten V-förmigen Falte CFv auf der Cardia und über den Cardiarand hinaus, zieht auf den Oesophagus beiderseits der Dorsalen Oesophagusklappe zu und biegt über die Vorderkanten des Oesophagus, wobei jeder obere und untere Teil Faserbündel austauscht. Oberer und unterer Teil divergieren nun ihrerseits, überqueren den obersten Abschnitt der lateralen Oesophaguswand und ziehen zur Cardiawand hinüber; der obere Teil greift über dem. M. dilatator cardiae lateralis $I$ im unteren Randbereich der Lateralplatten an, der untere Teil unter der Kante zwischen dem ventralen Querwulst des Oesophagus und dem Cardiakalen Ventralstück.

(21) M. constrictor cardiae (constr. car.) (Abb.17-19). Das breite Muskelband, das aus mehreren Bündeln besteht, greift jederseits der Cardia an der Oberkante und dem oberen Teil der Vorderkante der Lateralplatten an und umschließt, unter dem Cardiaboden hindurchlaufend, korbförmig die untere Cardiahälfte. Der hintere Abschnitt des Muskels entsendet ein kleineres Bündel auf die cardiakale Seitenwand hinter die halbmondförmige Einsenkung des hinteren Teiles des Cardiakalen Laterale CLp. 
(22) $M$. retractor exterior des Cardiakalen Dorsalstückes (retr. ext. CD), paarig (Abb. 17, 18). Der Muskel verläuft von der Kante der Cardiakalen Querfalte CFq auf dem Rüdken der Cardia abwärts zur Außenkante des Cardiakalen Dorsolaterale CDI.

(23) $M$. retractor interior des Cardiakalen Dorsalstückes (retr. int. CD), paarig (Abb. 17, 18). Der Muskel verläuft innerhalb des eben genannten $M$. retractor exterior von der Kante der Cardiakalen Querfalte CFq abwärts zum Cardiakalen Dorsolaterale $\mathrm{CDl}$, an dessen äußerem Rand jedoch nur der innere Abschnitt des Muskels angreift, während der äußere Abschnitt verdeckt hinter dem $M$. retractor exterior auf dem Rücken des Cardiakalen Dorsolaterale inseriert.

\section{Die Muskulatur des Pylorus}

(24) M. promotor des Cardiakalen Dorsalstückes (prom. CD) (Abb. 17-19) besteht aus zwei starken Muskelpaaren, die hintereinander am dorsalen Integument über dem vorderen Teil des Herzens entspringen. Sie verlaufen konvergierend über dem unpaaren Dorsalcoekum hinweg nach vorn unten und greifen jederseits auf dem Außenrand des Zipfels an, den die dorsale Pyloruswand über dem Cardiakalen Dorsalstïck CD bildet.

(25) $M$, dilatator pylori superior I (dil. pyl. s. I), paarig (Abb. 17-19), entspringt am dorsalen Integument auf halbem Weg zwischen der Nackenfurche im Carapax und dem Ansatz des $M$. promotor des Cardiakalen Dorsalstückes, zieht steil abwärts jederseits an der Aorta descendens vorbei, zwischen den $M$. promotor des Cardiakalen Dorsalstückes hindurch, biegt dann im letzten Abschnitt kopfwärts und greift hinter der Grube an, die das Pylorusdach hinter dem Cardiakalen Dorsalstück bildet.

(26) $M$. dilatator pylori superior II (dil. pyl. s. II), paarig (Abb. 17-19), entspringt direkt hinter dem $M$. dilatator pylori superior $I$ am dorsalen Integument, zieht parallel mit diesem abwärts zwischen den Partnern des $M$. promotor des Cardiakalen Dorsalstückes hindurch, wendet sich dann auswärts und greift außen am Pylorusdach an.

(27) M. dilatator pylori obliquns (dil. pyl. obliq.), paarig (Abb. 17-19), entspringt auf der Sehne des Mandibelmuskels außen vom $M$. dilatator cardiae inferior, steigt schräg nach hinten an, dabei außen auf dem $M$. constrictor pylori entlangziehend, bis er im letzten Abschnitt den $M$. pylori posterolateralis $I$ überquert, unter dem $M$. pylori posterolateralis II verschwindet und auf dem erweiterten Endabschnitt der Dorsalen Rinne angreift.

(28) M. protractor des Pylorikalen Ventralstückes (protr. PV), paarig (Abb. 17-19), entspringt am seitlichen Integument direkt über $\operatorname{dem} M$. dilatator oesophagi lateralis $I I$ und $I I I$, verläuft rückwärts und einwärts unter $\operatorname{dem} M$. dilatator oesophagi posterior $I$ hindurch, außen am $M$. dilatator oesophagi posterior $I I$ und $I I I$ vorbei, weiter zwischen den Partnern des $M$. dilatator cardiae inferior hindurch, vereinigt sich dann mit seinem Partner, durchstößt als unpaarer Muskel den $M$. constrictor pylori und greift vorn unten am Pylorikalen Ventralstïck an.

(29) M. constrictor pylori (constr. pyl.) (Abb. 17-19), ein breites Muskelband, das aus mehreren Bündeln besteht, greift jederseits des Pylorus am Uberhang des Pylorusdaches beziehungsweise am unteren Rand der Dorsalen Rinnen an und um- 
schließt, unter dem Pylorusboden hindurchlaufend, korbartig den Pylorus. Am vorderen Ende, wo der Protraktor des Pylorikalen Ventralstückes ihn durchstößt, greift er um die Vorderkante des Pylorus herum etwas nach oben, und während er im vorderen Abschnitt der pylorikalen Seitenwand den $M$. pylori anterolateralis $I$ und $I I$ zum Teil bedeckt, ist die hintere obere Ecke unter $\operatorname{dem} M$. pylori posterolateralis $I$ verborgen. Am hinteren Rand entsendet er einen schmalen Strang, der nach hinten verläuft und unterhalb des $M$. pylori posterolateralis am äußersten Punkt des Unteren Endstückes des Pylorus PLpi angreift.

Auf der Ventralseite des Pylorus bildet der $M$. constrictor ein Muskelgeflecht dadurch, daß die quer verlaufenden Ringmuskeln Stränge abzweigen, die in die Längsrichtung umbiegen und am Pylorusboden auf der Ringmuskelschicht entlang nach hinten verlaufen, auf der Rückwand des Pylorus sich fortsetzen und dort unter der rudimentären Verschlußklappe des Pylorus PVK angreifen. Einige dieser Muskelzüge, die von der Rückwand des Pylorus kommen, ziehen zusätzlich als dünne Stränge unter der Ringmuskelschicht über die ganze Länge des Pylorusbodens nach vorn und kehren in einem ellipsenförmigen Bogen zurück, um wieder in den Längsmuskelzügen aufzugehen (Abb. 19).

Tabelle 2

Die Muskeln des Labrum und Magens von Neomysis vulgaris

\begin{tabular}{|c|c|c|}
\hline & & \multirow{3}{*}{$\begin{array}{l}\text { Oberlippe } \\
\text { M. protractor I-VIII der Rückwand des } \\
\text { Labrum, paarig } \\
\text { M. contractor des Labrum, paarig } \\
\text { M. transversus des Labrum, unpaar. }\end{array}$} \\
\hline$(1)-(8)$ & L I-L VIII & \\
\hline $\begin{array}{r}(9) \\
(10)\end{array}$ & $\begin{array}{l}\operatorname{LrX} \\
\operatorname{LX}\end{array}$ & \\
\hline \multicolumn{3}{|r|}{ Oesophagus } \\
\hline $\begin{array}{l}(1)-(5) \\
(6)-(8) \\
(9)-(11) \\
(12)\end{array}$ & $\begin{array}{l}\text { dil. oe. a. I-V } \\
\text { dil. oe. I. I-III } \\
\text { dil. oe. p. I-III } \\
\text { constr. oe. }\end{array}$ & $\begin{array}{l}\text { M. dilatator oesophagi anterior } I-V \\
\text { M. dilatator oesophagi lateralis } I-I I I \\
\text { M. dilatator oesophagi posterior } I-I I I \\
\text { M. constrictor oesophagi }\end{array}$ \\
\hline & & Cardia \\
\hline $\begin{array}{l}(13)-(15) \\
(16) \\
(17)-(18) \\
(19) \\
(20) \\
(21) \\
(22) \\
(23)\end{array}$ & $\begin{array}{l}\text { dil. car. a. I-III } \\
\text { dil. car. la. } \\
\text { dil. car. I. I-II } \\
\text { dil. car. i. } \\
\text { retr. car. } \\
\text { constr. car. } \\
\text { retr. ext. CD } \\
\text { retr. int. CD }\end{array}$ & $\begin{array}{l}\text { M. dilatator cardiae anterior } I-I I I \\
M \text {. dilatator cardiae lateroanterior } \\
M . \text { dilatator cardiae lateralis } I-I I \\
M \text {. dilatator cardiae inferior } \\
M . \text { retractor cardiae } \\
M . \text { constrictor cardiae } \\
\text { M. retractor exterior I des Cardiakalen } \\
M . \text { retractor interior f Dorsalstidckes }\end{array}$ \\
\hline \multicolumn{3}{|r|}{ Pylorus } \\
\hline $\begin{array}{l}(24) \\
(25)-(26) \\
(27) \\
(28) \\
(29) \\
(30) \\
(31)\end{array}$ & $\begin{array}{l}\text { prom. CD } \\
\text { dil. pyl. s. I-II } \\
\text { dil. pyl. obliq. } \\
\text { protr. pV } \\
\text { constr. pyl. } \\
\text { pyl. al. } \\
\text { pyl. pl. }\end{array}$ & $\begin{array}{l}\text { M. promotor des Cardiakalen Dorsalstïckes } \\
\text { M. dilatator pylori superior } I-I I \\
\text { M. dilatator pylori obliquns } \\
\text { M. protractor des Pylorik. Ventralstückes } \\
\text { M. constrictor pylori } \\
\text { M. pylori anterolateralis } \\
\text { M. pylori posterolateralis }\end{array}$ \\
\hline
\end{tabular}


(30) M. pylori anterolateralis (pyl. al.), 2 Paar, (Abb. 17-19), verlaufen zwischen dem Winkel, den die Einstülpung der Pylorikalen Superolateralia an ihrem Anfang mit der pylorikalen Seitenwand bilden, und der hügelförmigen Erhebung, die die pylorikale Seitenwand jederseits vor dem Pylorikalen Wandfilter und unter dem Pylorikalen Inferolaterale aufweist.

(31) M. pylori posterolateralis (pyl. pl.), 2 Paar (Abb. 17-19), verlaufen zwischen der Dorsalen Rinne, auf deren erweitertem Endteil sie angreifen, und der Außenkante des Unteren Endstückes des Pylorus. Das vordere Paar bedeckt dabei in seinem oberen Teil den $M$. constrictor pylori, das hintere den Endabschnitt des $M$. dilatator pylori obliquus.

Die Muskeln des Labrum und Magens von Neomysis vulgaris sind noch einmal übersichtlich in Tabelle 2 zusammengestellt worden.

\section{Die Funktion des Magens und seiner Muskulatur}

Der Weg der Nahrung durch den Magen sei nur der Vollständigkeit wegen kurz erwähnt, da er den Gegebenheiten entspricht, wie sie allgemein bei Malakostraken vorliegen.

Nach dem Passieren des Oesophagus steigt die Nahrung zunächst im vordersten Teil der Cardia aufwärts, da der Weg auf dem Magenboden entlang nach hinten durch die nach innen vorspringenden Lateralfalten mit ihren Borstensystemen versperrt ist. Von oben gelangen die Nahrungsteile dann zwischen die Lateralplatten. Schon hier in der Cardia beginnt der Prozeß der Durchmischung mit den Verdauungssekreten, die aus den Mitteldarmdrüsen beziehungsweise dem Dorsalcoekum nach vorn gelangen. Die beweglichen Magenteile, die Lateralia und Dorsolateralia sowie das Cardiakale Ventralstück, wirken mit ihren Borsten wie ein Rührwerk und pressen die Nahrung zum Teil auch schon aus. Die entstehende Flüssigkeit wird durch das Borstengitter über den Cardiakalen Ventralrinnen gefiltert und gelangt in den Pylorus und weiter in die Mitteldarmdrüsen. Der Nahrungsbrei gelangt allmählich durch den Engpaß zwischen Cardia und Pylorus in die nach hinten zu immer enger werdende Nahrungsrinne zwischen den Supero- und Inferolateralia des Pylorus. Die pressende Wirkung der Wände wird nach hinten zu stärker, die Nahrungsflüssigkeit wird durch die verschiedenen Borstengitter des Pylorus gefiltert und gelangt durch die Dorsalrinnen, die Filterrinnen im Pylorikalen Ventralstück, im Wandfilter oder noch durch die Lücken des Pylorikalen Borstenkorbes in die Mitteldarmdrüsen. Der unverdaute Rest wird durch das Pylorikale Dorsalstück als ein führendes Rohr in den Enddarm geleitet.

Die Wirkungsweise der Magenmuskulatur ergibt sich wie folgt. Die Erweiterung des Oesophagus erfolgt durch die Dilatatoren $M$, dilatator oesophagi anterior $I-V$, lateralis $I-I I I$, posterior $I-I I I$ (Abb. 15, 17-19), die an den Kanten des Oesophagus oder in den Wandeinfaltungen angreifen. Die Verengung des Oesophagus bewirkt das Ringmuskelsystem des $M$. constrictor oesophagi (Abb. 19). Besonders zu erwähnen ist der $M$. dilatator oesophagi anterior $I$, der am oberen Rand der Dorsalen Oesophagusklappe ODK angreift und diese im ganzen nach vorn zu ziehen vermag, wodurch eine zusätzliche Erweiterung des Mageneinganges erfolgt (Abb. 19). Als Ant- 

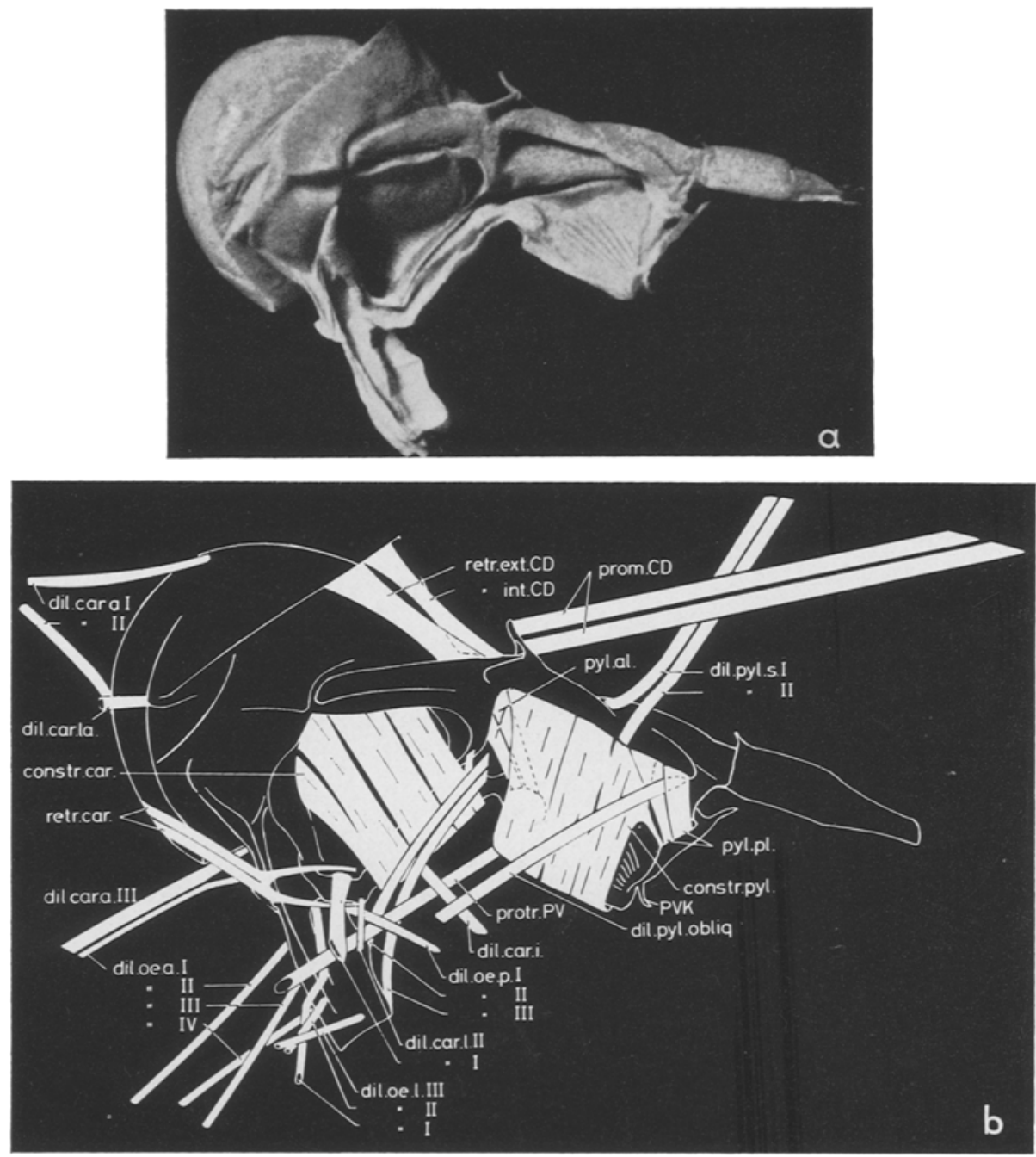

Abb. 17: Kaumagen von Neomysis vulgaris. (a) Kalilaugepräparat, versilbert; Auflichtfoto von lateral. (b) Die Magenmuskulatur von lateral, rekonstruiert nach Schnitt- und Sektionspräparaten. Verzeichnis der Muskeln siehe Tabelle 2

agonist wirkt der Längsmuskelstrang des Constrictormuskels des Oesophagus auf der dorsalen Oesophaguswand, der zwischen den Partnern des $M$. dilatator anterior $I$ hindurchläuft und in den einzelnen Ringmuskelstrang des Constrictormuskels des Oesophagus über dem oberen Rand der Dorsalen Oesophagusklappe einmündet (Abb. 19). Seine Kontraktion drückt die Dorsale Oesophagusklappe nach hinten und bewirkt den Verschluß des Mageneinganges.

Durch den Aufbau der Cardia bei den Mysideen, der eine starke und aktive Lumenerweiterung ermöglicht, ist mit einem Sog zu rechnen, der die Wirkung der 

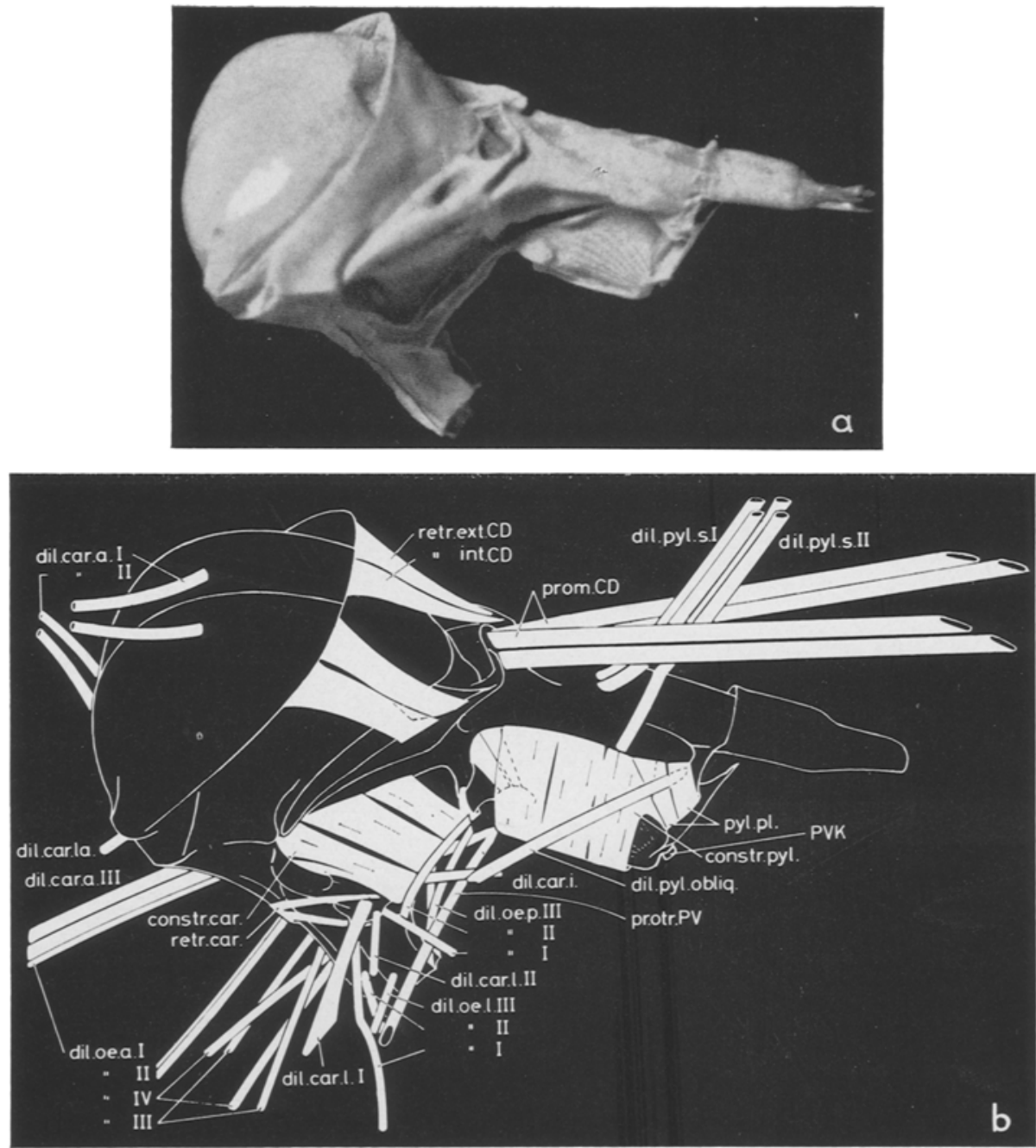

Abb. 18: Kaumagen von Neomysis vttgaris. (a) Kalilaugepräparat, versilbert; Auflichtfoto von dorsolateral. (b) Die Magenmuskulatur von dorsolateral, rekonstruiert nach Schnitt- und Sektionspräparaten. Verzeichnis der Muskeln siehe Tabelle 2

Oesophagusdilatatoren erhöht. Die Lumenerweiterung ergibt sich durch das Aufspringen der großen unpaaren Querfalte CFq und der paarigen Vertikalfalte CFv (Abb. 2). Bei diesem Vorgang sind die 4 Paar vorderen Dilatatoren der Cardia sowie die beiden $M$. retractor cardiae beteiligt.

Der $M$. dilatator cardiae anterior I (dil. car. a. I) übt einen vorwärtsgerichteten Zug auf den oberen Teil der Cardiakappe aus, der sich in eine kreisförmige Bewegung umsetzt, da nur das Cardiadach dem Zug nachgibt, indem sich die Querfalte CFq öffnet. Die Drehpunkte der Kreisbewegung sind die seitlichen Endpunkte der Querfalte 

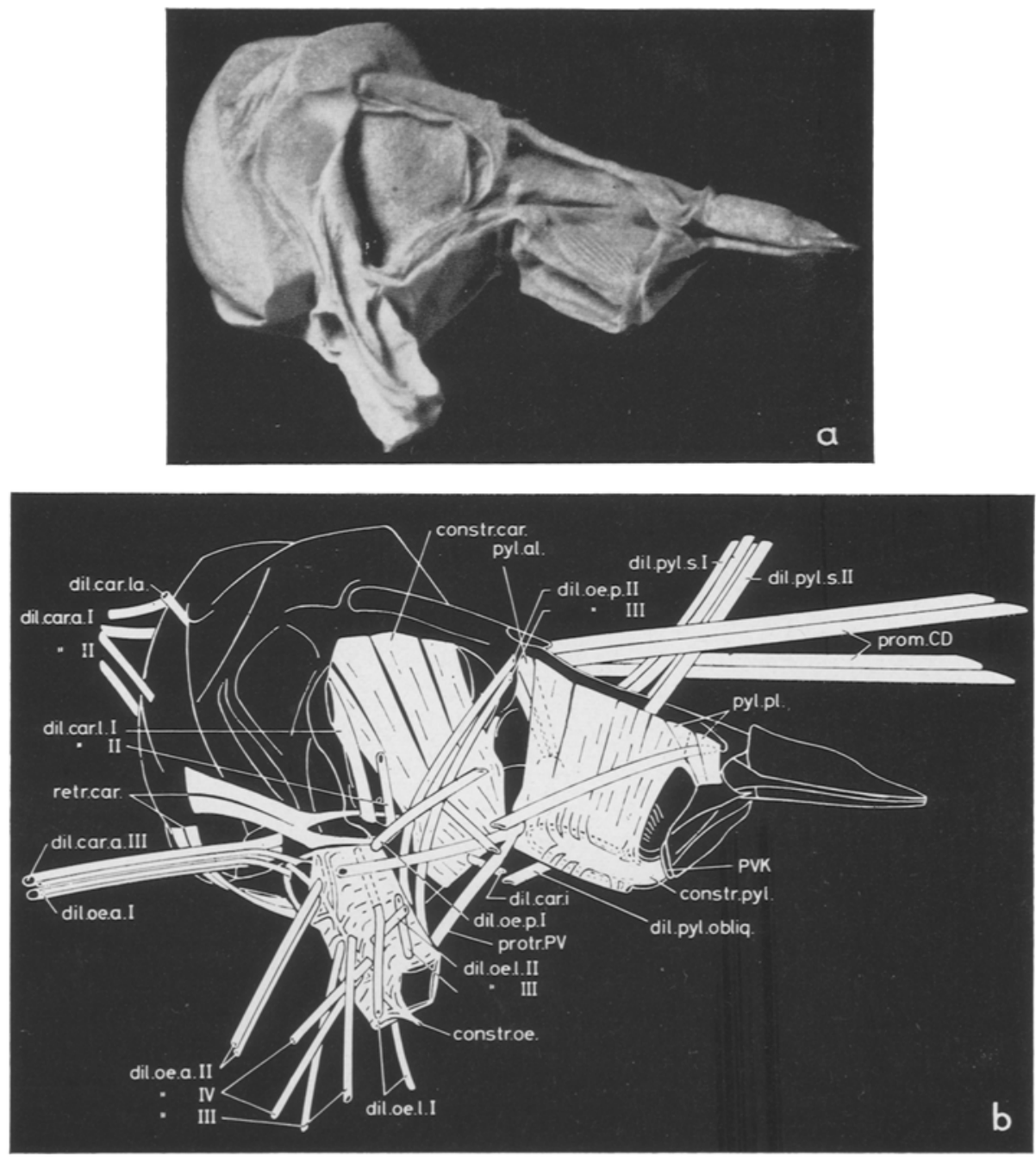

Abb. 19: Kaumagen von Neomysis vulgaris. (a) Kalilaugepräparat, versilbert; Auflichtfoto von ventrolateral. (b) Die Magenmuskulatur von ventrolateral, rekonstruiert nach Schnittund Sektionspräparaten. Verzeichnis der Muskehn siehe Tabelle 2

$\mathrm{CFq}$, die durch die kurzen $M$. dilatator lateroanterior (dil. car. la.) vorn seitlich an der Körperwand fixiert sind, allerdings nicht in direkter Verlängerung der Drehachse.

Als Antagonist, für die rückläufige Kreisbewegung, die zum Schließen der Querfalte führt, dient der $M$. dilatator cardiae anterior $I I I$ (dil. car. a. III), der in der Kehle zwischen Cardia und Oesophagus angreift (Abb. 17-19). Das Offnen und Schließen der Querfalte ist die einzige Bewegung des Magens, die am lebenden Tier zu beobachten ist; von dorsal, wo die Cardia bis dicht unter die Körperoberfläche reicht, ist der Vorgang als Vor- und Abwärtsrutschen der Cardia wahrzunehmen. 
Der $M$. dilatator cardiae lateroanterior (dil. car. la.) dient nicht nur zur elastischen Aufhängung der Cardia bei der Drehbewegung, sondern bewirkt zusammen mit den beiden $M$. dilatator cardiae anterior II (dil. car. a. II) das Offnen der paarigen Vertikalfalte $\mathrm{CFy}$ vorn auf der Cardia. Indem der $M$. dilatator cardiae lateroanterior (dil. car. la.) auf den Außenkanten der Falten ansetzt, der $M$. dilatator cardiae anterior II dagegen auf der Magenkappe zwischen den beiden Falten, die ihren gemeinsamen funktionellen Innenrand darstellt, springen die Falten bei Kontraktion der beiden Muskelpaare auf (Abb. 17-19). Als Antagonisten wirken die beiden M. retractor cardiae (retr. car.), die außerdem mit einer rückwärts gerichteten Komponente die Drehwirkung des vorwärts gerichteten Zuges $\operatorname{des} M$. dilatator cardiae anterior $I$ (dil. car. a. I) auf die Cardiakappe und damit das Offnen der Querfalte CFq unterstützen (Abb. 17, 19). Entsprechend kann der $M$. dilatator cardiae anterior II (dil. car. a. II) außer beim Offnen der Vertikalfalten CFy beim Schließen der Querfalte CFq mitwirken, indem er dem Vorwärtszug der $M$. dilatator cardiae anterior III (dil. car. a. III) eine Aufwärtskomponente hinzufügt (Abb. 17, 19). An der lateralen Wand der Cardia bewirkt der $M$. dilatator cardiae lateralis $I$ (dil. car. 1 . I), der am unteren Rand der großen Lateralplatten CLa angreift, daß diese voneinander entfernt werden. Am Cardiaboden inseriert der $M$. dilatator cardiae inferior (dil. car. i.), der das Cardiakale Ventralstück CV abwärts zieht. Der Antagonist für die beiden zuletzt genannten Muskelpaare ist der $M$. constrictor cardiae (constr. car.) (Abb. 17, 19).

Die Funktion der auf dem Rücken der Cardia zwischen Querfalte CFq und Cardiakalem Dorsalstück $C D$ verlaufenden beiden Muskelpaare, der $M$. retractor exterior (retr. ext. CD) und interior (retr. int. CD) des Cardiakalen Dorsalstückes, besteht einerseits darin, die beiderseits von oben in die Cardia ragenden Chitinzahnpaare der Cardiakalen Dorsolateralia CDI nach außen-oben zu ziehen wie die Backen einer Baggerschaufel. Andererseits bewirken sie die rückwärtsgerichtete Bewegung des Cardiakalen Dorsalstückes $\mathrm{CD}$ und sind damit die Antagonisten der beiden doppelten $M$, promotor des Cardiakalen Dorsalstückes (prom. CD), die dieses nach vorn bewegen (Abb. 17, 18).

Die Aufgabe der $M$. dilatator pylori superior $I$ und $I I$ (dil. pyl. s. I, II) liegt in der Erweiterung des dorsalen Pylorusraumes bzw. der Dorsalen Rinnen des Pylorus. Damit unterstïtzen sie den Transport einerseits der von den Mitteldarmdrüsen bzw. vom Dorsalcoekum nach vorn strömenden Verdauungssekrete, andererseits des gefilterten Nahrungssaftes und des Filterrückstandes nach hinten.

Im hintersten Teil des Pylorus entfaltet der $M$. dilatator pylori obliquus (dil. pyl. obliq.) den erweiterten Endabschnitt der Dorsalen Rinnen, wogegen der M. pylori posterolateralis (pyl. pl.) als Antagonist wirkt (Abb. 17-19).

Der $M$. protractor des Pylorikalen Ventralstückes (protr. PV) zieht dieses nach vorn unten, durch die Kontraktion des $M$. constrictor pylori (constr. pyl.) kehrt es nach hinten oben zurück (Abb. 17-19,9b).

Der M. constrictor bestimmt außerdem die Stellung der Supero- und Inferolateralia des Pylorus, wie weit sie sich nähern bzw. überlappen. Er beeinflußt auch den Drudk auf den Stauraum zwischen diesen beiden Faltenpaaren, in dem der Nahrungsbrei ausgepreßt wird.

Schließlich ist noch der M. pylori anterolateralis (pyl. al.) zu erwähnen, der einen 


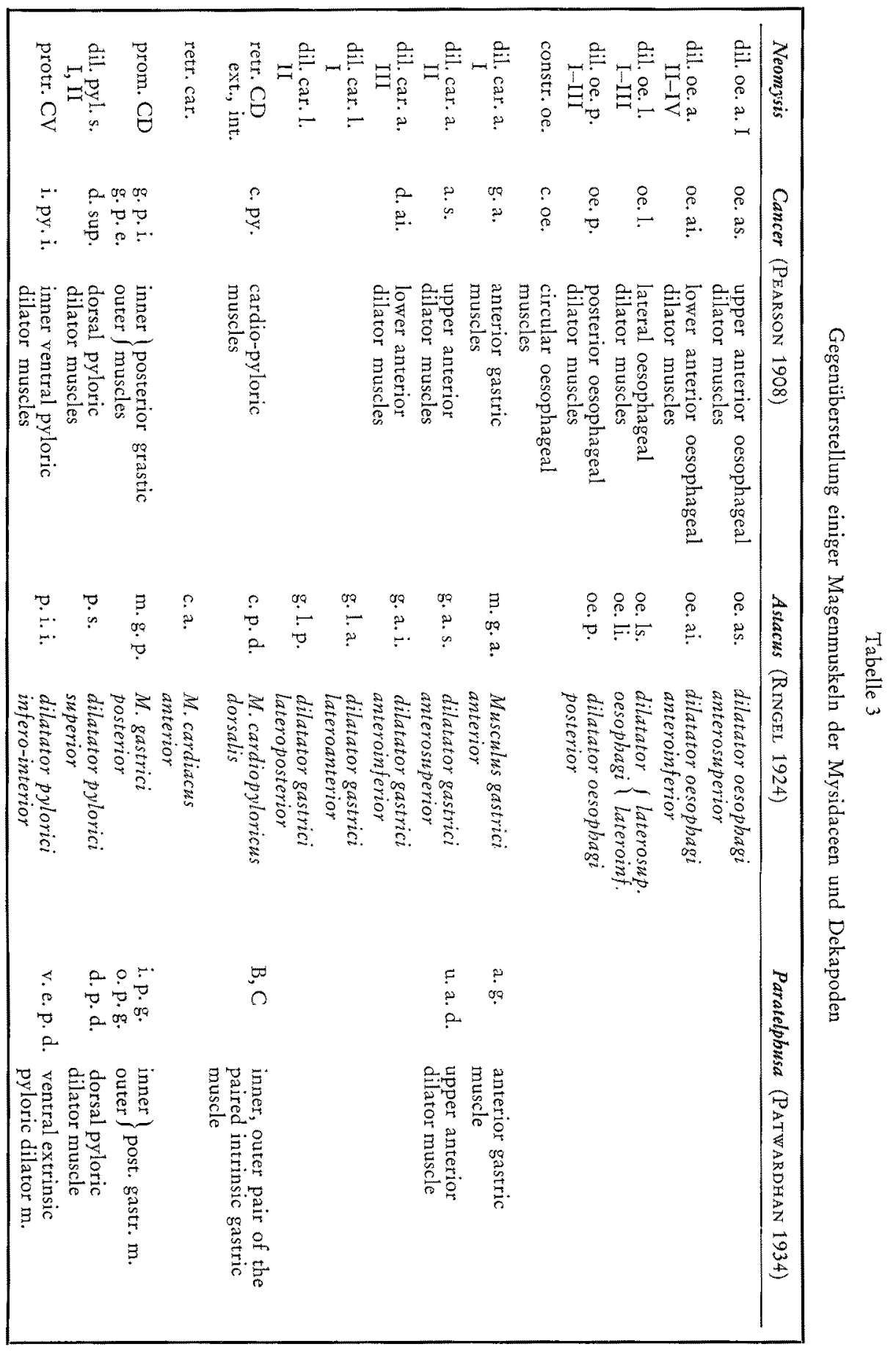


abwärts wirkenden Zug auf den vorderen Abschnitt der Dorsalwülste ausübt, der sich als Druck auf den Nahrungsbrei auswirkt (Abb, 17-19).

Ein Vergleich mit den Magenmuskeln der Dekapoden ist nur in sehr beschränktem Umfange möglich. Die Angaben über Cancer (PEArson 1908), Astacus (Ringel 1924) und Paratelphusa (PATWARDHan 1934), drei Vertreter der Decapoda Reptantia, zeigen den Abbildungen nach untereinander und im Vergleich zu Neomysis für einige Muskeln Ubereinstimmungen der Lage nach. Diese Muskeln sind in Tabelle 3 gegenübergestellt. Eine Homologisierung vorzunehmen, erscheint mir nicht gerechtfertigt, solange nicht genauere Untersuchungen besonders an Vertretern der Decapoda Natantia und an Lophogastrida, der Basisgruppe der Peracarida, vorliegen. Bei den Reptantia weisen offensichtlich weder die Cardia noch der Pylorus einen so einheitlichen Constrictormuskel auf wie zum Beispiel Neomysis. Mit der stärkeren Aufteilung der Magenwände und Verkalkung einiger Magenteile scheint bei den Reptantia eine Auflösung dieser Muskeln in kleinere Einheiten einhergegangen zu sein.

\section{DIE MAGEN DER PERACARIDA UND EUCARIDA}

Die Verwendung von Totalpräparaten der Chitinintima von Kaumägen malakostraker Krebse gestattet einen direkten Vergleich dieser komplizierten Gebilde. Sie machen besser als Schnittpräparate augenfällig, wie weitgehend in den verschiedenen Mägen die gleichen Stücke vertreten sind. Ihre im gemeinsamen Verband gleichbleibende Einordnung - bei unterschiedlicher Form und Ausprägung in den einzelnen Gruppen ermöglicht die Identifizierung und Homologisierung.

Die folgenden Stücke setzen typischerweise den Malakostrakenmagen zusammen (Abb. 2): Im Oesophagus sind es Dorsale, Ventrale und Laterale Oesophagusfalten OD, OV, OL beziehungsweise -klappen ODK, OVK, OLK - so genannt, wenn sie sich abheben und über die Oesophagusgrenze in die Cardia ragen; in der Cardia ein Cardiakales Dorsalstück CD, ein Cardiakales Dorsolaterale CDI, ein Cardiakales Ventralstïck CV und zwei Lateralstïcke (ein Cardiakales Laterale CLa + CLp und ein Cardiakales Inferolaterale CLi). Im Pylorus sind es wiederum ein Pylorikales Dorsalstück PD, ein Pylorikales Ventralstück PV, eine ventrale Pylorikale Verschlußklappe PVK und mehrere Lateralstïcke: ein Pylorikales Superolaterale PLs, ein Pylorikales Inferolaterale PLi, ein Oberes Endstück PLps und ein Unteres Endstück PLpi. Dazu können. in einzelnen Gruppen weitere Faltenbildungen auftreten oder einige der genannten wegfallen.

Die Besprechung der verschiedenen Magenformen der Eucarida und Peracarida erfolgt hier in einer vergleichenden Übersicht. Mit der Nomenklatur wurde wie bei der Beschreibung des Magens von Neomysis verfahren. Die Bezeichnungen früherer $\mathrm{Au}-$ toren sind in den Tabellen 5 bis 8 zusammengefaßt worden. 


\section{Mysidacea}

Der Magen des Lophogastriden Gnathophausia ingens zeigt manche Züge, die auch bei den Isopoden zu beobachten sind, und andere, die auch die Dekapoden aufweisen. Die Lage des Cardiakalen Dorsalstückes CD an der Stirn des Magens, die starke Ausprägung des vorderen Teiles des Cardiakalen Laterale CLa gegenüber dem hinteren Teil CLp sowie die Überschneidung der cardiakalen und pylorikalen Lateralfalten weisen auf den Isopodenmagen hin; die Stellung des Oesophagus, die Ausbildung und Anordnung des Pylorikalen Dorsalstïckes PD und des Unteren Endstückes PLpi, die der bei Neomysis entsprechen, Zahl und Art der Pylorikalen Filterrinnen PF sowie die typische Form der Pylorikalen Verschlußklappe PVK erinnern an den Dekapodenmagen. Im übrigen entspricht die Ausbildung der Teile am Lophogastridenmagen Eucopia weicht nur in den Proportionen unwesentlich von Gnathophausia ab - der bei Neomysis beschriebenen. Am Oesophagus ist umgekehrt wie bei Neomysis die Ventrale Oesophagusklappe OVK tiefer eingestülpt als die Dorsale Oesophagusklappe ODK; die Form des Cardiakalen Laterale, dessen hinterer Teil CLp unbewaffnet ist, ist nicht so klar im Umriß; zu betonen ist auch, daß das Untere Endstück PLpi bei Gnathophansia (Abb. 20e) viel stärker ausgebildet ist als bei Neomysis (Abb. 2b, 12, 13).

Am Magen von Neomysis (Abb. 20f) überlappen die Lateralia beider Magenabschnitte nicht. Die Cardia ist blasenförmig aufgetrieben, und das Cardiakale Dorsalstück CD liegt am hinteren Ende der Cardia an der Grenze zum Pylorus. Der hintere Teil des Cardiakalen Laterale CLp ist mit Chitinzähnen bewaffnet. Alles das sind Merkmale, die auch den Eucaridenmagen kennzeichnen (Abb. 20g, h, i). Die Verlagerung des Cardiakalen Dorsalstückes von der Magenstirn an die Cardia-Pylorus-Grenze läßt sich dadurch erklären, daß die Aufblähung der Cardia von dem Teil der dorsalen Magenwand ausgegangen ist, der beim Lophogastridenmagen vor dem Cardiakalen Dorsalstück liegt, wodurch diese Einfaltung nach hinten verlagert wurde. Dafür spricht auch die relative Lage der Cardiakalen Dorsolateralia CDl zum Cardiakalen Dorsalstück CD bei Neomysis, die in Anordnung und Form genau zwei Einsenkungen entsprechen, die - wenn auch unbewaffnet - neben dem Cardiakalen Dorsalstück bei Gnathophausia liegen (Abb. 20e, f).

\section{Euphausiacea}

Sehr auffällig sind die Ubereinstimmungen von Neomysis und Thysanoëssa spinifer, einem Vertreter der Euphausiaceen (Abb. 20f, i), was die Ausbildung der Cardiakappe, Lage und Form des Cardiakalen Dorsalstiickes CD, des Cardiakalen Dorsolaterale CD1 und des hinteren Teiles des Cardiakalen Laterale CLp angeht. Die Cardiakappe ist bei Thysanoëssa durch eine doppelte Falte CFq - Zimmer (1956) nennt sie "dorsale Ringfurche (drf)" - gekennzeichnet, nicht durch eine einfache wie Neomysis, das Cardiakale Dorsalstück CD ist bei Thysanoëssa nicht wie bei Neomysis mit Borsten versehen. Dagegen zeigt das Cardiakale Dorsolaterale CDI bei beiden die gleiche Bewaffnung mit Chitinzähnen, die bei den Euphausiaceen schwächer, dafür aber in größerer Zahl vorhanden sind (etwa 5). Ebenso ist es mit dem hinteren Teil des Cardia- 
kalen Laterale CLp, der bei beiden Formen die gleichen Chitinzähne trägt, die ebenfalls bei Thysanoëssa kleiner, aber zahlreicher sind (etwa 10). Der vordere Teil des Cardiakalen Laterale CLa der Euphausiaceen entspricht in seiner langgestreckten einfachen Form den Gegebenheiten bei den Dekapoden und ist damit ein gemeinsames Merkmal der Eucarida gegenüber den Mysidaceen.

Ein eigenes Charakteristikum des Euphausiaceenmagens ist das auffallend schlanke Pylorikale Ventralstück PV, das ebenso wie die pylorikale Seitenwand weder Filterrinnen noch Borsten aufweist.

\section{Decapoda}

Die Anordnung des Pylorikalen Dorsalstückes PD und des Unteren Endstückes PLpi entspricht bei den Eucarida der bei Neomysis beschriebenen, nur ist bei Sergestes (Abb. 20h), wie wohl überhaupt bei den Penaeidea, die pylorikale Seitenwand zwischen diesen beiden Stücken weit nach hinten verlängert, flach eingesenkt und beborstet, wodurch ein zusätzliches Faltenpaar entsteht (Abb. 20h: F). PATw ARDHAN (1935) nennt hier nicht nur ein Paar, sondern "two pairs of elongated valves"; wahrscheinlich ist mit dem zweiten Paar das infolge der Streckung der pylorikalen Seitenwand nach hinten verlagerte Untere Endstück PLpi gemeint. Sergestes weist über dem Cardiakalen Laterale CL eine zusätzliche Falte auf, die auch schon PATwardhan (1935) für die Sergestidae allgemein nennt.

Die Dekapodenmägen (Abb. $20 \mathrm{~g}, \mathrm{~h}$ ) zeigen ebenfalls die schon bei Mysideen und Euphausiaceen beobachtete typische Aufblähung der Cardia, jedoch mit einer besonderen Art der Faltenbildung. Zahlreiche längsverlaufende Fältchen lassen die Cardiakappe der Dekapoden wie zerknittert erscheinen. Besonders ausgeprägt ist diese Erscheinung bei den Eucyphidea, zu denen Palaemonetes (Abb. 20g) gehört. PATWARDHAN (1935) spricht von einem "bellows with a number of irregular longitudinal folds". Eine Sonderbildung der Eucyphidea scheinen die beiden Einfaltungen $\mathrm{cp}$ und $\mathrm{lp}$ zu sein, die Palaemonetes (Abb. 20g) an Stirn und Vorderdach der Cardia aufweist; Patwardhan (1937) nennt sie "circulate plate“ und "lanceolate plate“. Ein weiterer Punkt, in dem die Eucyphidea auffallen, ist die Ausbildung des Cardiakalen Ventralstïckes CV: es ist wie bei den Euphausiaceen und Peracarida nach oben hochgewölbt, während es bei allen anderen Dekapoden zum größten Teil nach unten durchhängt und eine mediane Rinne bildet; nur der letzte Abschnitt, der dem freien Zipfel des Cardiakalen Ventralstückes bei den anderen Formen entspricht, ragt in der gewohnten Weise als mehr oder weniger ausgebildete Klappe an der Cardiopylorikalgrenze aufwärts (Abb. 20h).

Das charakteristische Merkmal des Dekapodenmagens, die Magenmühle aus Mittelzahn und Seitenzähnen, ist bei Sergestes ohne Zweifel als zum Cardiakalen Dorsalstück CD und zum hinteren Abschnitt des Cardiakalen Laterale CLp gehörig zu identifizieren. Im Magen von Palaemonetes dagegen ist die Magenmühle reduziert, jedoch läßt die relative Lage der Magenteile zueinander keinen $Z_{\text {weifel daran, daß auch }}$ dieser Magen dem oben genannten Bauplan entspricht.

Nach Patwardhan (1935) haben die Mägen der meisten Eucyphidea den Habitus des Palaemonetes-Magens, jedoch gibt es auch Vertreter, und zwar in den Familien 
Atyidae (Caridina) und Hippolytidae (Hippolyte, Virbius), deren Mägen noch die Cardiaform der Penaeidea haben, wobei die Magenmühle schwach, aber noch deutlich ausgebildet ist. Auf Grund der Lagekorrelation der Teile, einerseits in der Reduktionsreihe Penaeidea - Atyidae, Hippolytidae - übrige Eucyphidea, andererseits bei Penaeidea und Reptantia, vollzog PATWARdhan die Homologisierung der dem Cardiakalen Dorsalstück CD, dem hinteren Abschnitt des Cardiakalen Laterale CLp und dem freien Zipfel des Cardiakalen Ventralstückes entsprechenden Stücke für alle Dekapoda. Diese Aussage läßt sich auf Grund der hier vorliegenden Ergebnisse erweitern: D i e Magenteile, welchedie Magenmühlezusammensetzen, sind $\mathrm{k}$ e in e Sonderbild ung der Deka poden. Sie gehören vielmehr - ebenso wie die übrigen Teile des Magens - durchaus zum allgemeinen Bauplan des Malakostrakenmagens.

Kehren wir nun an den Anfang dieser vergleichenden Betrachtung zurück und wenden uns den Gruppen der Peracarida zu, die die Lage des Cardiakalen Dorsalstückes CD, die starke Ausprägung des vorderen Abschnittes des Cardiakalen Laterale CLa und die Überschneidung der Seitenteile des Magens mit Gnathophausia gemeinsam haben: Amphipoden, Cumaceen, Tanaidaceen und Isopoden (Abb. 20d, c, b, a).

\section{Amphipoda}

Am Magen von Gammarus (Abb. 20d) überlappen die cardiakalen und pylorikalen Seitenteile zwar nicht, aber der vordere Abschnitt des Cardiakalen Laterale CLa ist wie in den noch folgenden Gruppen stark ausgeprägt. Der hintere Abschnitt des Cardiakalen Laterale CLp ist großflächig und nur am oberen Rand eingesenkt. Ein Cardiakales Inferolaterale CLi ist nicht ausgebildet. Das Cardiakale Dorsalstück liegt wie bei Gnathophausia an der Magenstirn, ist jedoch nur in Form einer flachen Einsenkung ohne Borstenbesatz vorhanden. Die Pylorikale Verschlußklappe PVK gleicht der des Lophogastridenmagens und damit dem Typ, der auch bei den Eucarida zu finden ist. Das Untere Endstück der pylorikalen Seitenwand PLpi ist in das Pylorikale Dorsalstück PD eingegangen und nur noch als seitliche Rinne in diesem auszumachen.

Mit der Lage des Cardiakalen Dorsalstückes CD, der Ausbildung des Cardiakalen Laterale CLa + CLp, dem mit dem Pylorikalen Dorsalstück vereinigten Unteren Endstück der pylorikalen Seitenwand PD + PLpi weist der Amphipodenmagen Merkmale auf, die auch bei den Isopoden ausgeprägt sind; an die Dekapoden erinnert lediglich die Pylorikale Verschlußklappe PVK.

\section{Cumacea, Tanaidacea, Isopoda}

Die Mägen von Paratanais (Abb. 20b), Diastylis (Abb. 20c) und Idotea (Abb. 20a) gleichen einander in vielen Punkten. Sie zeigen alle eine Streckung sowie eine Vereinheitlichung der Form; der Oesophagus mündet von vorn in die Cardia, der vordere Abschnitt des Cardiakalen Laterale CLa ist stark ausgeprägt und bewaffnet, die Lateralia des Pylorus PLs und PLi greifen weit auf cardiakales Gebiet vor, und das Untere 
Endstück der pylorikalen Seitenwand PLpi ist mit dem Pylorikalen Dorsalstück PD vereinigt.

Das Cardiakale Dorsalstück CD (Abb, 20a) formt bei den Isopoden mit Ausnahme der Landasseln eine fingerförmige Einstülpung an der Stirn des Magens. Bei den Landisopoden ist allgemein das breite kurze Dach der Cardia von den Seiten zur Mittellinie leicht eingesenkt, ein eigentliches Dorsalstück aber nicht ausgeprägt. Unklar bleiben die Verhältnisse in diesem Punkt bei den Cumaceen und Tanaidaceen. Paratanais weist zwar eine Einstülpung auf, die nach Lage und Form dem Cardiakalen Dorsalstück der Isopoden entspricht, jedoch bildet unmittelbar dahinter das Magendach eine weitere Einsenkung, die breit und stark beborstet ist. Damit gleicht diese sehr der einzigen dorsalen Cardiafalte, die der Magen von Diastylis aufweist.

Unmittelbar hinter dieser $z$ weiten folgt bei Paratanais eine dritte Einsenkung, die tief und trogförmig ist. Zur Klärung dieser Frage bedarf es wohl der Untersuchung weiterer Vertreter der Cumaceen und Tanaidaceen. Die drei Dorsalstücke des Magens von Paratanais sind in Abbildung $20 \mathrm{~b}$ mit D I, II, III bezeichnet, das einzige Dorsalstück bei Diastylis, das dem zweiten bei Paratanais zu entsprechen scheint, in $\mathrm{Ab}$ bildung 20c mit D II; STAPPERs (1909) beschreibt diese Falte als „saillie supérieur de l'estomac (sse)“, Zimmer (1941) als „kardiakales Dorsalstück“ beziehungsweise „obere Pylorikalklappe“.

Die zweite Dorsalfalte D II bei Paratanais ist noch insofern bemerkenswert, als ihr Boden eine doppelte Chitinschicht aufweist und damit an jene Bildungen der pylorikalen Seitenwand erinnert, die gegenüber den pylorikalen Filterrinnen liegen können: sie wurden für Asellus (ReHorst 1914) und für Ligia (Nicholls 1931) als „elastische Kissen" oder "elastic pads" beschrieben.

Zum Uberschneiden der Seitenteile bei den Isopoden ist zu sagen, daß das Pylorikale Superolaterale PLs vorwärts bis über den vorderen Abschnitt des Cardiakalen Laterale CLa greift, während das Vorrücken des Pylorikalen Inferolaterale PLi bewirkt, daß bei den Isopoden zum Teil die Cardiakalen Inferolateralia CLi beziehungsweise die zu diesen gehörigen Borstensäume auseinanderweichen, indem die hinteren Teile nach außen abbiegen und dann über den vorderen Abschnitt der Pylorikalen Inferolateralia PLi ragen - beispielsweise bei Ligia, Idotea und den Landasseln. Das Cardiakale Ventralstück wird dabei in der Größe reduziert; bei Asellus spaltet es vorn auf, der Oesophagusmündung ausweichend, und erscheint in der Aufsicht yförmig. Bei den Cumaceen, Tanaidaceen und Landisopoden ist der Magen dorsal dicht hinter dem Cardiakalen Dorsalstück zu Ende, demzufolge zieht die aus Pylorikalem Dorsalstück PD und Unterem Endstück der pylorikalen Seitenwand PLpi vereinigte Falte als schmaler Falz vom ventralen Magenende nach vorn aufwärts. Bei den Isopoden im allgemeinen ist das Verschmelzungsprodukt eine an den Seiten lang ausgezogene Einfaltung, die dorsal nicht so weit nach hinten reicht und so einen dorsalen Ausschnitt aufweist. Dieser wird teilweise ausgefüllt durch eine Sonderbildung, die als charakteristisches Merkmal des Isopodennagens gelten kann. Eine flache Einfaltung senkt sich auf dem Pylorusdach vor dem Pylorikalen Dorsalstück ein, verläuft parallel unter diesem und über diesen hinaus nach hinten; es sei Akzessorisches Dorsalstück des Pylorus PAD genannt. Die Namen, unter denen es von verschiedenen Autoren für einige Isopoden beschrieben worden ist, sind den zusammenfassenden Tabellen 5 bis 8 zu entnehmen. 
Besonders deutlich ist das Akzessorische Dorsalstück PAD am Magen der Landasseln zu beobachten, der ja dorsal stark verkürzt ist und das Pylorikale Dorsalstück nur als schmalen Falz aufweist. Die Pylorikale Verschlußkappe PVK ist bei den Isopoden nicht in einer so typischen und einheitlichen Form ausgebildet wie bei Lophogastriden, Amphipoden und Eucarida, sondern beispielsweise lang und lappig, wie bei Ligia und Idotea, oder paarig-wurstförmig, wie bei den Landisopoden. Bei Cumaceen und Tanaidaceen erinnert die Form an die Mysidaceen.

Zusammenfassend läßt sich sagen: die Mägen der Euc a rida und Peracarida sind grundsätzlich nach einem gemeinsamen Bauplan gebaut. Innerhalb dieses Rahmens haben sie abereinen Isopodentyp und einen Dekapodentyp ausgebildet, die mit-

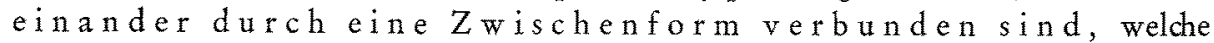
Merkmale beider Typen in sich vereinigt.

Den D ek a podenty p zeichnet eine klare Trennung von Cardia und Pylorus aus, eine charakteristische Aufblähung der Cardia und, daraus folgend, die Verlagerung des Cardiakalen Dorsalstïckes CD an die Cardiopylorikalgrenze; der hintere Abschnitt des Cardiakalen Laterale CLp wird stärker bewaffnet und bildet bei den Dekapoden mit dem ebenfalls extrem bewaffneten Cardiakalen Dorsalstïck CD die Magenmühle. Bei Mysideen und Euphausiaceen dagegen wird weniger das Cardiakale Dorsalstiick $\mathrm{CD}$, als vielmehr das Cardiakale Dorsolaterale CDI deutlicher ausgebildet und mit Chitinzähnen versehen; das Pylorikale Ventralstück PV ist mit zahlreichen Filterrinnen ausgestattet, teilweise auch die pylorikale Seitenwand diesen gegenüber in Form des Pylorikalen Wandfilters PW; das Pylorikale Dorsalstück PD und das Untere Endstück der pylorikalen Seitenwand PLpi sind getrennt ausgebildet; die Pylorikale Verschlußkappe PVK ist in Form einer mehr oder weniger schlanken Zipfelmütze vorhanden.

Der I s o po de n t y p dagegen zeichnet sich durch folgende Merkmale aus: Der Habitus ist gestreckt, da der Oesophagus von vorn in die Cardia mündet und die cardiakalen und pylorikalen Teile ineinandergreifen. Dadurch wird bei den Isopoden das Cardiakale Ventralstück CV in der Größe reduziert oder spaltet, wie bei Asellus, vorn auf. Das Pylorikale Superolaterale PLs greift teilweise nach vorn bis über den vorderen Abschnitt des Cardiakalen Laterale CLa, der im Gegensatz zum Dekapodentyp stärker ausgeprägt und bewaffnet wird. Das Vorgreifen des Pylorikalen Inferolaterale PLi bewirkt teilweise ein Auseinanderweichen der beiden Partner des Cardiakalen Inferolaterale CLi beziehungsweise ihrer Borstensäume, die dann auf dem vorderen Teil des Pylorikalen Inferolaterale aufliegen. Das Untere Endstück der pylorikalen Seitenwand PLpi ist in das Pylorikale Dorsalstück PD einbezogen und die aus beiden gebildete Falte bildet bei Cumaceen, Tanaidaceen und Landisopoden nur noch einen schmalen Falz. Bei den Isopoden ist im Gegensatz zu den Amphipoden ein Akzessorisches Dorsalstück PAD ausgebildet, das sich vor dem eigentlichen Dorsalstück des Pylorus einsenkt und unter diesem nach hinten verläuft. Das Pylorikale Ventralstück PV ist mit höchstens zwei pylorikalen Filterrinnen ausgestattet und die Pylorikale Verschlußklappe PVK hat eine variable Form.

Den Zwischentyp repräsentiert der Lophogastridenmagen. Er vereinigt Merkmale des Isopodentyps (Ausbildung der Cardia, Lage des Cardiakalen 


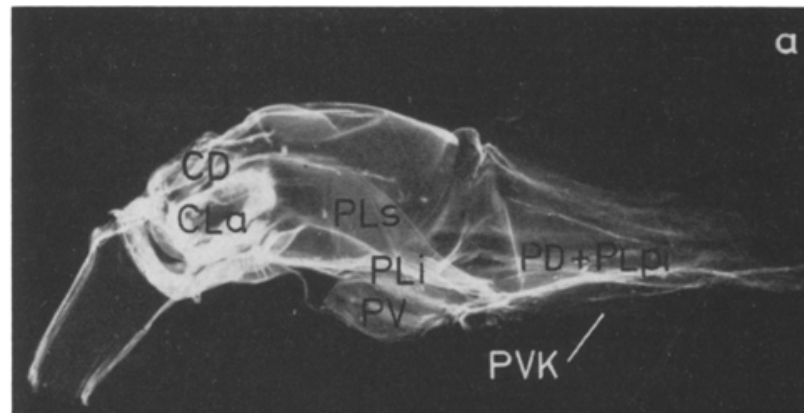

\section{Idotea}

$1+5$

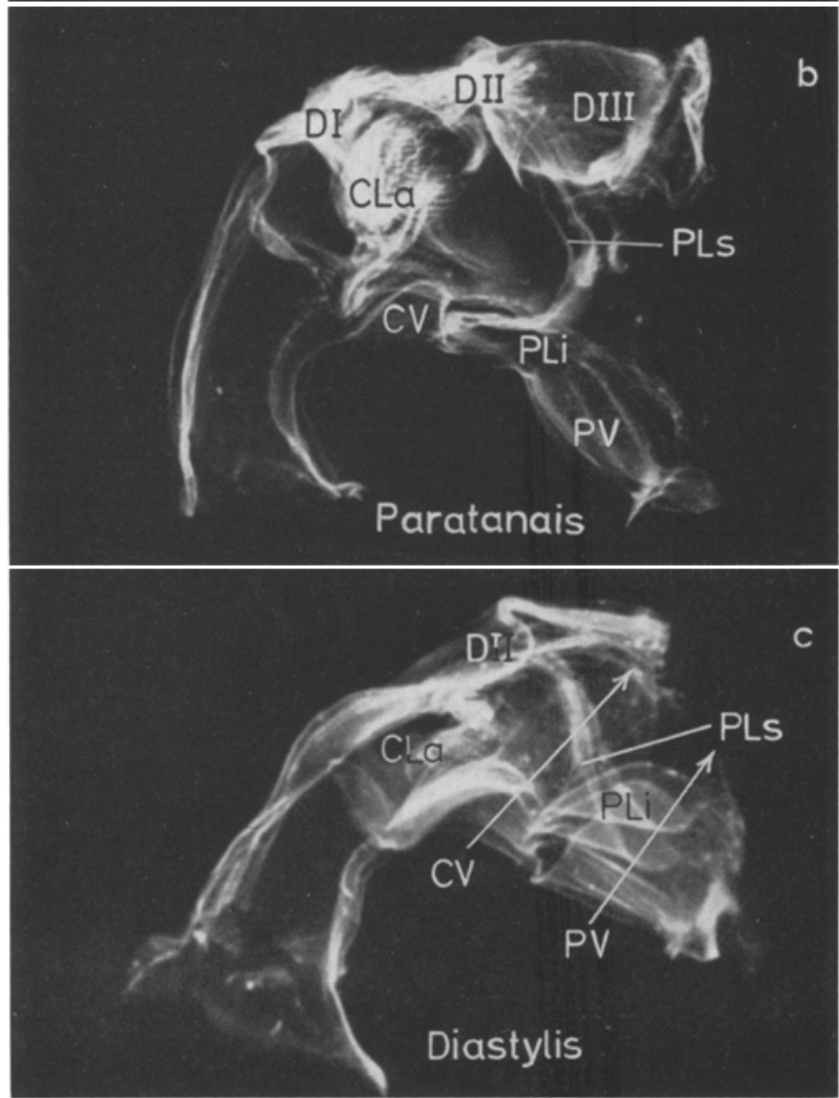

Abb. 20a-c: Kaumägen von Idotea, Paratanais und Diastylis in Seitenansicht. Näheres Tabelle 1 und im Text 

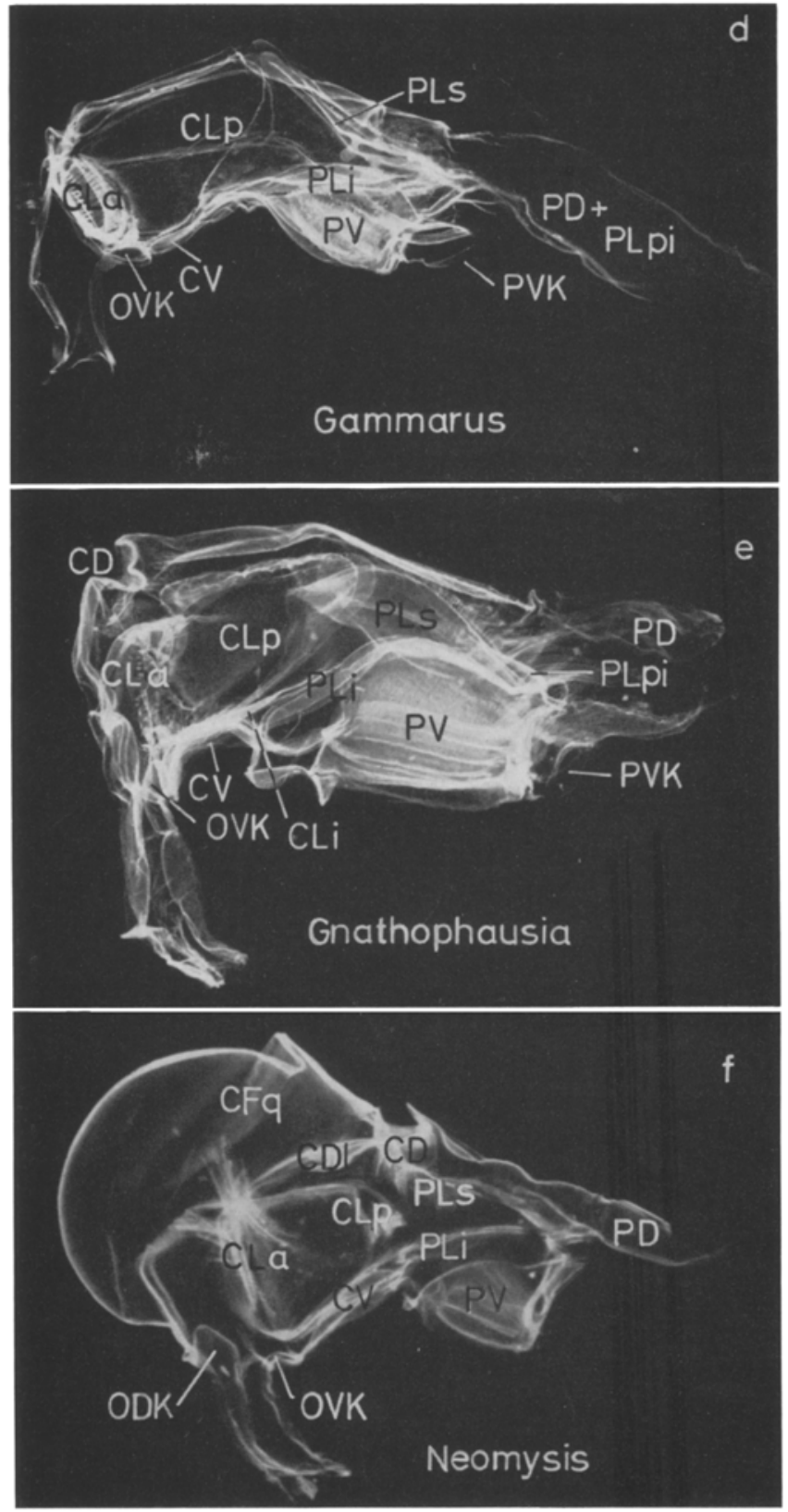

Abb. 20d-f: Kaumägen von Gammarus, Gnathophausia und Neomysis in Seitenansicht. Näheres in Tabelle 1 und im Text 

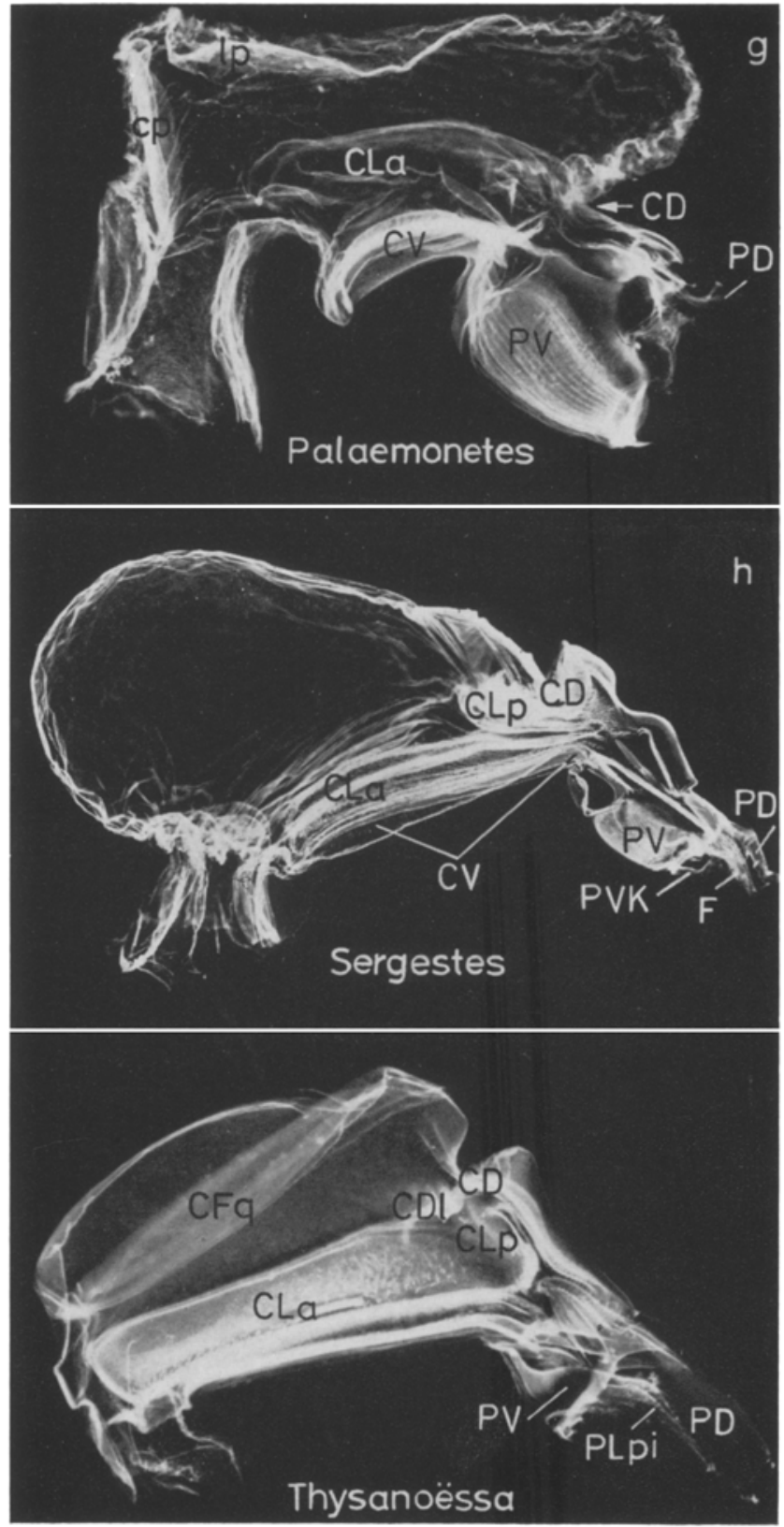

Abb. $20 \mathrm{~g}-\mathrm{i}$ : Kaumägen von Palaemonetes, Sergestes und Thysanoëssa in Seitenansicht. Nähe res in Tabelle 1 und im Text 


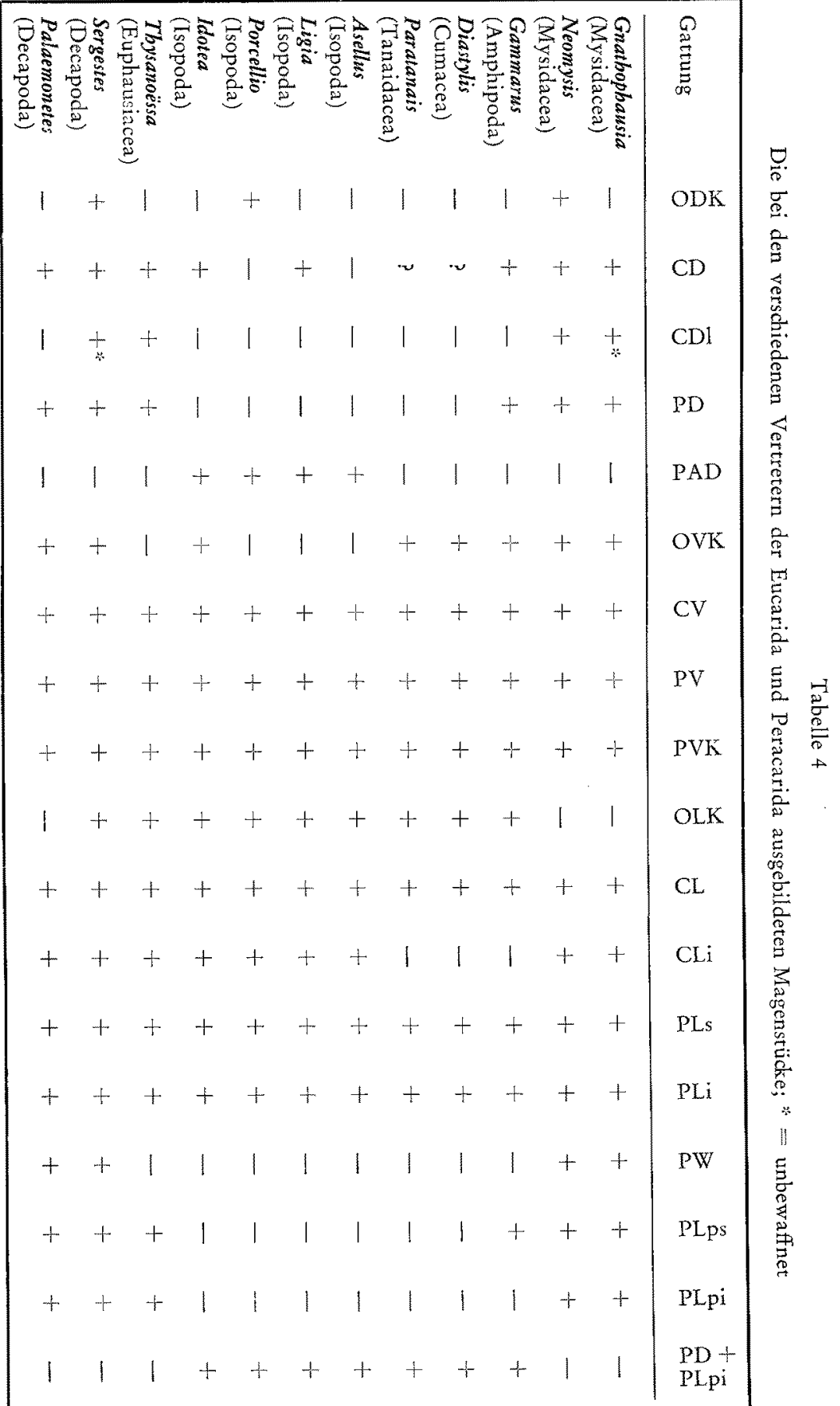


Tabelle 5

\begin{tabular}{|c|c|c|c|c|c|c|c|}
\hline & \multirow{3}{*}{ 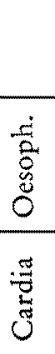 } & \multirow{3}{*}{$\frac{\mathrm{ODK}}{\mathrm{CD}}$} & \multirow{3}{*}{$\begin{array}{l}\text { Dorsale } \\
\text { Oesophagus- } \\
\text { klappe }\end{array}$} & \multicolumn{2}{|c|}{$\begin{array}{c}\text { Malacostraca } \\
\text { SIEWING (1957) }\end{array}$} & \multicolumn{2}{|c|}{$\begin{array}{c}\text { Mysidacea } \\
\text { GeLDERD }(1909)\end{array}$} \\
\hline \multirow{3}{*}{$\begin{array}{l}\bar{x} \\
\vdots \\
0 \\
0\end{array}$} & & & & OVK & $\begin{array}{l}\text { Oesophagus- } \\
\text { verschlußklappe }\end{array}$ & & \\
\hline & & & & $\mathrm{DH}$ & $\begin{array}{l}\text { Dorsale } \\
\text { Hakenplatte }\end{array}$ & psm & $\begin{array}{l}\text { superior } \\
\text { median } \\
\text { piece }\end{array}$ \\
\hline & $\frac{\mathscr{2}}{\frac{0}{2}}$ & $\begin{array}{l}\mathrm{PD} \\
\mathrm{PAD}\end{array}$ & $\begin{array}{l}\text { Pylorikales } \\
\text { Dorsalstück } \\
\text { Akzessorisches } \\
\text { Dorsalstück } \\
\text { des Pylorus }\end{array}$ & RST & Reststück & & \\
\hline & $\frac{\sqrt[3]{0}}{3}$ & $\mathrm{CV}$ & $\begin{array}{l}\text { Cardiakales } \\
\text { Ventralstüdi }\end{array}$ & $\mathrm{CV}$ & $\begin{array}{l}\text { Cardiakales } \\
\text { Ventralstüds }\end{array}$ & $\mathrm{c}$ & $\begin{array}{l}\text { longitudinal } \\
\text { ridge of car- } \\
\text { diac chamber }\end{array}$ \\
\hline$\stackrel{5}{5}$ & $\frac{2}{\frac{2}{2}}$ & $\begin{array}{l}\text { PV } \\
\text { PVK }\end{array}$ & $\begin{array}{l}\text { Pylorikales } \\
\text { Ventralstuick } \\
\text { Pylorikale } \\
\text { Verschluß- } \\
\text { klappe }\end{array}$ & PM & $\begin{array}{l}\text { Pylorikales } \\
\text { Mittelstüdk }\end{array}$ & $\begin{array}{l}\text { Sis } \\
\times \\
\times\end{array}$ & $\begin{array}{l}\text { median piece } \\
\text { of pyloric } \\
\text { chamber } \\
\text { small } \\
\text { eminence }\end{array}$ \\
\hline \multirow{3}{*}{ 莣 } & 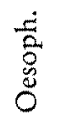 & OLK & $\begin{array}{l}\text { Laterale } \\
\text { Oesophagus- } \\
\text { klappe }\end{array}$ & & & & \\
\hline & 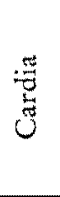 & CLi & $\begin{array}{l}\text { Cardiakales } \\
\text { Laterale } \\
\text { Cardiakales } \\
\text { Inferolaterale }\end{array}$ & $\begin{array}{l}\text { Ls } \\
\text { Li }\end{array}$ & $\begin{array}{l}\text { Laterale, } \\
\text { superior, } \\
\text { inferior }\end{array}$ & $\begin{array}{l}s_{1} \\
b_{s} \\
b_{1}\end{array}$ & $\begin{array}{l}\text { lateral piece } \\
\text { of card. chamber } \\
\text { upper border } \\
\text { of } S_{1} \\
\text { under border } \\
\text { of } S_{1}\end{array}$ \\
\hline & $\frac{\mathscr{E}}{E}$ & $\begin{array}{l}\text { PLps } \\
\text { PLpi }\end{array}$ & $\begin{array}{l}\text { Pylorikales } \\
\text { Superolaterale } \\
\text { Pylorikales } \\
\text { Inferolaterale }\end{array}$ & $\begin{array}{l}\text { DW } \\
\text { PST } \\
\text { PBK }\end{array}$ & $\begin{array}{l}\text { Dorsalwulst } \\
\text { Pylorikales } \\
\text { Seitenstüd } \\
\text { Pylorikaler } \\
\text { Borstenkorb }\end{array}$ & $\begin{array}{l}\mathrm{br}_{1} \\
+ \\
\mathrm{S}_{1 \mathrm{~s}} \\
\mathrm{~S}_{2} \\
\mathrm{brz}_{2} \\
+ \\
\mathrm{S}_{11} \\
\mathrm{P}_{21} \\
\mathrm{P}_{2} \mathrm{l}_{2}\end{array}$ & $\begin{array}{l}\text { fold }+ \\
\text { upper fold of } \\
\text { pyloric chamber } \\
\text { lateral piece of } \\
\text { pyloric chamber } \\
\text { fold }+ \\
\text { lower fold of } \\
\text { pyloric chamber } \\
\text { upper terminal } \\
\text { piece of } S_{2} \\
\text { lower terminal } \\
\text { piece of } S_{2}\end{array}$ \\
\hline & & $\begin{array}{l}\text { PD } \\
+ \\
\text { PLpi }\end{array}$ & & & & & \\
\hline
\end{tabular}


Zusammentassende Ubersicht

\begin{tabular}{|c|c|c|c|c|c|c|}
\hline & $\begin{array}{l}\text { Lophogastrida } \\
\text { IEWING (1952) }\end{array}$ & \multicolumn{2}{|c|}{$\begin{array}{c}\text { Caprellidae } \\
\text { MAYER }(1883)\end{array}$} & $\begin{array}{c}\text { Gammaridae } \\
\text { DELLA VALLE }(1893)\end{array}$ & \multicolumn{2}{|r|}{$\begin{array}{l}\text { Amphipoda } \\
\text { THIEM (1942) }\end{array}$} \\
\hline \multicolumn{7}{|c|}{$\begin{array}{l}\text { OVK Oesophagus- } \\
\text { verschlußklappe }\end{array}$} \\
\hline $\mathrm{DH}$ & $\begin{array}{l}\text { Dorsale } \\
\text { Hakenplatte }\end{array}$ & & & & & \\
\hline $\mathrm{RS}$ & Reststïck & & & & & \\
\hline $\mathrm{CV}$ & $\begin{array}{l}\text { Cardiakales } \\
\text { Ventralstüd }\end{array}$ & & & & $S_{1}$ & $\begin{array}{l}\text { Cardiakales } \\
\text { Mittelstüd }\end{array}$ \\
\hline \multirow[t]{4}{*}{ PM } & $\begin{array}{l}\text { Pylorikales } \\
\text { Mittelstïick }\end{array}$ & & $\begin{array}{l}\text { mediane } \\
\text { Zunge }\end{array}$ & $\begin{array}{l}\text { pgv piega gastrica } \\
\text { ventrale }\end{array}$ & $\mathrm{S}_{3}$ & $\begin{array}{l}\text { Pylorikales } \\
\text { Mittelstïick }\end{array}$ \\
\hline & & & $\begin{array}{l}\text { medianes } \\
\text { Sädkchen }\end{array}$ & & $\mathrm{K}$ & Kolben \\
\hline & & & & & Zoe & $\begin{array}{l}\text { Zungen der la- } \\
\text { teralen Oeso- } \\
\text { phagusfalte }\end{array}$ \\
\hline & $\begin{array}{l}\text { Cardiakale } \\
\text { Seitenfalte }\end{array}$ & & & $\begin{array}{l}\text { pc = piega gastrica } \\
\text { pgla } \\
\text { pglm p. g. laterale } \\
\text { media }\end{array}$ & $\begin{array}{l}\text { DW } \\
\text { DP } \\
\text { VF }\end{array}$ & $\begin{array}{l}\text { Dors. Seitenwulst } \\
\text { Dornenpresse } \\
\text { Ventralfalte }\end{array}$ \\
\hline PSS & $\begin{array}{l}\text { Pylorikales } \\
\text { Seitenstüdk }\end{array}$ & & $\begin{array}{l}2 \text { Paar } \\
\text { große } \\
\text { dreikantige } \\
\text { Platten }\end{array}$ & $\begin{array}{l}\text { pglp piega gastrica } \\
\text { laterale } \\
\text { posteriore }\end{array}$ & $\begin{array}{l}\text { DW } \\
\mathrm{S}_{2} \\
\mathrm{VW}\end{array}$ & $\begin{array}{l}\text { Dorsale } \\
\text { Seitenwülste } \\
\text { Seitenstüdke } \\
\text { Ventralwülste }\end{array}$ \\
\hline \multirow[t]{2}{*}{ PB } & $\begin{array}{l}\text { Pylorikaler } \\
\text { Borstenkorb }\end{array}$ & & & & $\mathrm{BK}$ & Borstenkorb \\
\hline & & & $\begin{array}{l}\text { unten } \\
\text { offenes } \\
\text { Rohr }\end{array}$ & $\begin{array}{l}\text { stmd stomodeo pen- } \\
\text { dente nella } \\
\text { cavità dell' } \\
\text { intestino medio }\end{array}$ & $\begin{array}{l}\text { LD } \\
+ \\
\text { Ls }\end{array}$ & $\begin{array}{l}\text { Leiste der } \\
\text { Dorsalwand }+ \\
\text { Reststück der } \\
\text { Seitenwand }\end{array}$ \\
\hline
\end{tabular}


Tabelle 6

\begin{tabular}{|c|c|c|c|c|c|}
\hline & & & & $\begin{array}{c}\text { Amphipoda } \\
\text { AGRAWAL (1963) }\end{array}$ & $\begin{array}{c}\text { Cumacea, Tanaidacea } \\
\text { CLAUS (1888) }\end{array}$ \\
\hline \multirow{3}{*}{$\begin{array}{l}\overline{2} \\
\frac{0}{0}\end{array}$} & $\begin{array}{l}\frac{5}{0} \\
0 \\
0 \\
0 \\
0\end{array}$ & ODK & $\begin{array}{l}\text { Dorsale } \\
\text { Oesophagus- } \\
\text { klappe }\end{array}$ & & \\
\hline & 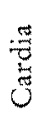 & $\mathrm{CD}$ & $\begin{array}{l}\text { Cardiakales } \\
\text { Dorsalstuick }\end{array}$ & DA dorsal ridge & $\begin{array}{c}\text { DHP dorsale haken- } \\
\text { tragende Platte } \\
\text { vgl. Text }\end{array}$ \\
\hline & $\frac{2}{0}$ & $\begin{array}{l}\text { PD } \\
\text { PAD }\end{array}$ & $\begin{array}{l}\text { Pylorikales } \\
\text { Dorsalstück } \\
\text { Akzessorisches } \\
\text { Dorsalstück } \\
\text { des Pylorus }\end{array}$ & & \\
\hline \multirow[b]{2}{*}{ 焉 } & $\frac{0}{0}$ & $\mathrm{CV}$ & $\begin{array}{l}\text { Cardiakales } \\
\text { Ventralstück }\end{array}$ & VA ventral ridge & ZW Zungenwulst \\
\hline & $\frac{5}{2}$ & $\begin{array}{l}\text { PV } \\
\text { PVK }\end{array}$ & $\begin{array}{l}\text { Pylorikales } \\
\text { Ventralstïck } \\
\text { Pylorikale } \\
\text { VerschluB- } \\
\text { klappe }\end{array}$ & $\begin{array}{l}\text { MVP mid-ventral } \\
\text { piece }\end{array}$ & $\begin{array}{l}\text { PW Pylorikaler } \\
\text { Medianwulst }\end{array}$ \\
\hline \multirow{3}{*}{ 胥 } & $\begin{array}{c}\frac{\tilde{E}}{8} \\
\dot{0} \\
0\end{array}$ & OLK & $\begin{array}{l}\text { Laterale } \\
\text { Oesophagus- } \\
\text { klappe }\end{array}$ & & $\begin{array}{c}\text { OeKLlaterale Oeso- } \\
\text { phagealklappen }\end{array}$ \\
\hline & $\frac{\tilde{z}}{3}$ & CLi & $\begin{array}{l}\text { Cardiakales } \\
\text { Laterale } \\
\text { Cardiakales } \\
\text { Inferolaterale }\end{array}$ & $\begin{array}{l}\text { DL dorso-lat. r. } \\
\text { LL lateral ridge } \\
\text { VL ventro-lat. } r .\end{array}$ & $\begin{array}{ll}\text { Ck } & \text { Cardiakalkiefer } \\
\text { CBL } & \text { Car. Borstenleiste } \\
\text { BW } & \text { Borstenwulst } \\
& \text { unterhalb LBL }\end{array}$ \\
\hline & $\frac{\mathscr{e}}{2}$ & $\begin{array}{l}\text { PLs } \\
\text { PLi } \\
\text { PLps } \\
\text { PLpi }\end{array}$ & $\begin{array}{l}\text { Pylorikales } \\
\text { Superolaterale } \\
\text { Pylorikales } \\
\text { Inferolaterale } \\
\text { Oberes } \\
\text { Endstudk } \\
\text { Unteres } \\
\text { Endstück }\end{array}$ & $\begin{array}{l}\text { DL dorsolat. } r \text {. } \\
\text { VL ventro-lat. } r \text {. }\end{array}$ & $\begin{array}{ll}\text { LBL } & \text { Laterale } \\
& \text { Borstenleiste } \\
\text { GF } & \text { Grenzfalte der } \\
& \text { Pyloruskammer }\end{array}$ \\
\hline
\end{tabular}


Zusammenfass $\in$ nde Ubersicht

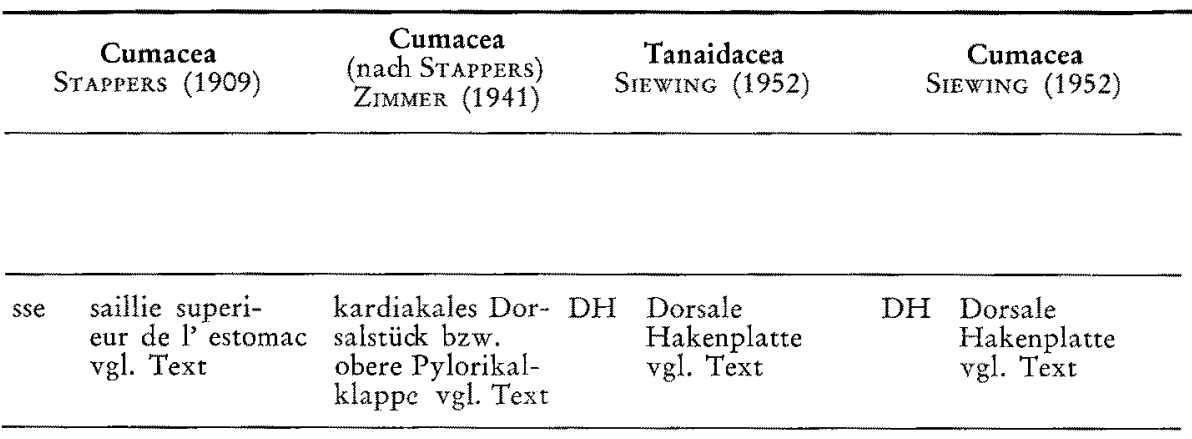

\begin{tabular}{llllll}
\hline pci & $\begin{array}{l}\text { pièce } \\
\text { cardiaque } \\
\text { inferieur }\end{array}$ & $\begin{array}{l}\text { kardiakales } \\
\text { Ventralstück }\end{array}$ & CV $\begin{array}{l}\text { Cardiakales } \\
\text { Ventralstiick }\end{array}$ & CV $\begin{array}{l}\text { Cardiakales } \\
\text { Ventralstïck }\end{array}$ \\
\hline $\begin{array}{l}\text { ppi pièce } \\
\begin{array}{l}\text { pylorique } \\
\text { pipferieur }\end{array}\end{array}$ & $\begin{array}{l}\text { pylorikales } \\
\text { Ventralstück }\end{array}$ & PM & $\begin{array}{l}\text { Pylorikales } \\
\text { Mittelstück }\end{array}$ & PM & $\begin{array}{l}\text { Pylorikales } \\
\text { Mittelstüdk }\end{array}$
\end{tabular}

\begin{tabular}{|c|c|c|c|c|c|c|}
\hline $\mathrm{Vc}$ & $\begin{array}{l}\text { valvula } \\
\text { cardiaca }\end{array}$ & $\begin{array}{l}\text { valvula } \\
\text { cardiaca }\end{array}$ & & & $\mathrm{VP}$ & $\begin{array}{l}\text { Vertikale Platten } \\
\text { am Eingang des } \\
\text { Kaumagens }\end{array}$ \\
\hline slas & $\begin{array}{l}\text { saillie } \\
\text { laterale } \\
\text { antero-sup. }\end{array}$ & $\begin{array}{l}\text { kardiakales } \\
\text { Seitenstück }\end{array}$ & $\begin{array}{l}\mathrm{CC} \\
\mathrm{LK}_{1} \\
\mathrm{LK}_{2}\end{array}$ & $\begin{array}{l}\text { Cardiakalkiefer } \\
\text { Lateralfalte } \\
1 \text { und } 2\end{array}$ & $\begin{array}{l}\text { Ls } \\
\text { Li } \\
\text { PSA } \\
\text { PLA }\end{array}$ & $\begin{array}{l}\text { Laterale sup. } \\
\text { Laterale inf. } \\
\text { Cardiak. Teil } \\
\text { der PST } \\
\text { Hintere } \\
\text { Seitenfalte }\end{array}$ \\
\hline $11 \mathrm{p}$ & $\begin{array}{l}\text { lames } \\
\text { latérales } \\
\text { pylorique }\end{array}$ & $\begin{array}{l}\text { pylorikales } \\
\text { Seitenstück }\end{array}$ & $\mathrm{LK}_{3}$ & Lateralfalte 3 & $\begin{array}{l}\text { DW } \\
\text { PST }\end{array}$ & $\begin{array}{l}\text { Dorsalwülste } \\
\text { Pylorikale } \\
\text { Seitenstücke }\end{array}$ \\
\hline
\end{tabular}


Tabelle 7

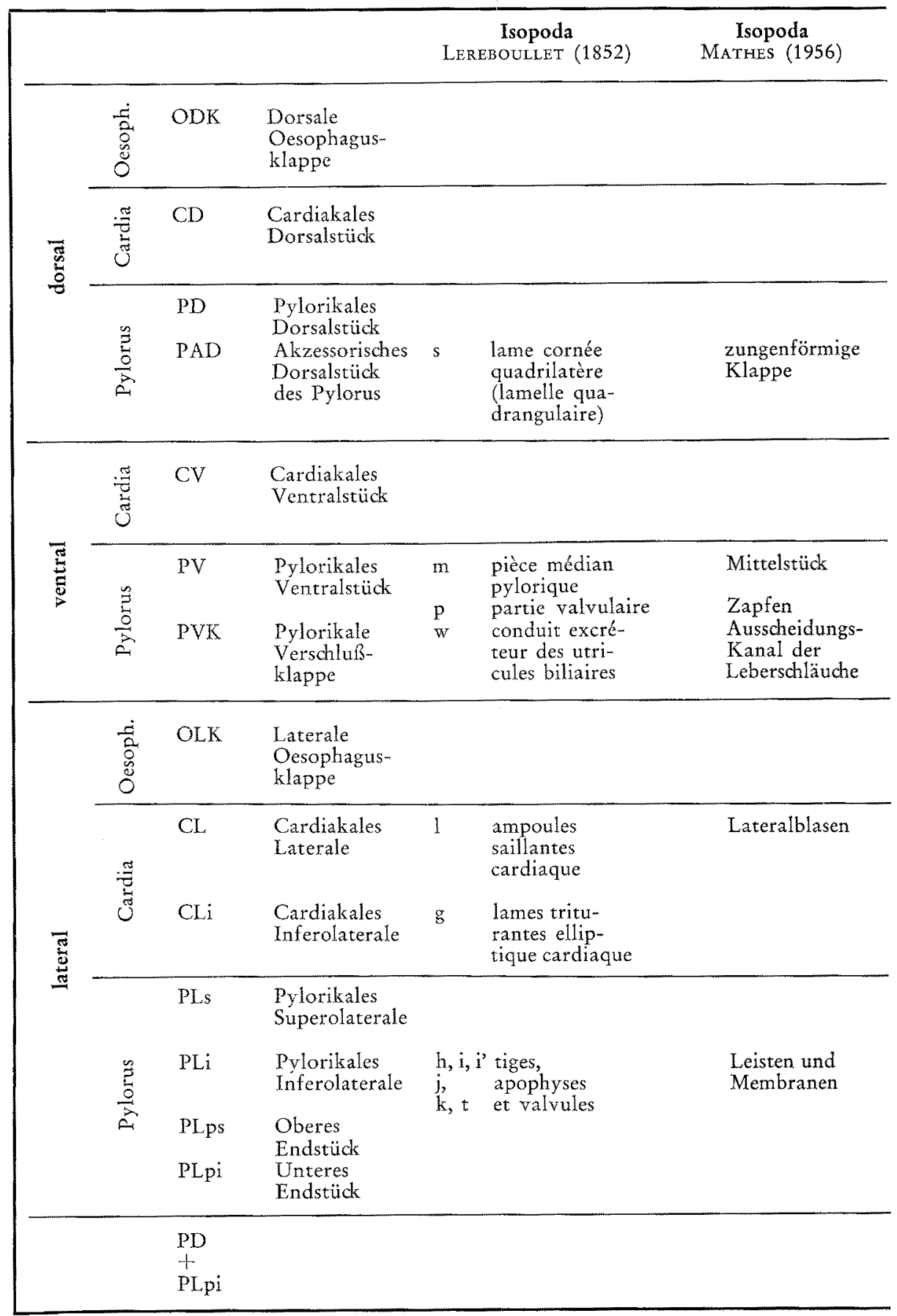


Zusammenfassende Ubersicht

\begin{tabular}{cccc|}
\hline $\begin{array}{c}\text { Isopoda } \\
\text { ScHÖвL (1860) }\end{array}$ & Isopoda & "Edriophthalmen“ & Isopoda \\
& SCHÖNICHEN (1899) & IDE (1892) & HEWITT (1907) \\
\hline
\end{tabular}

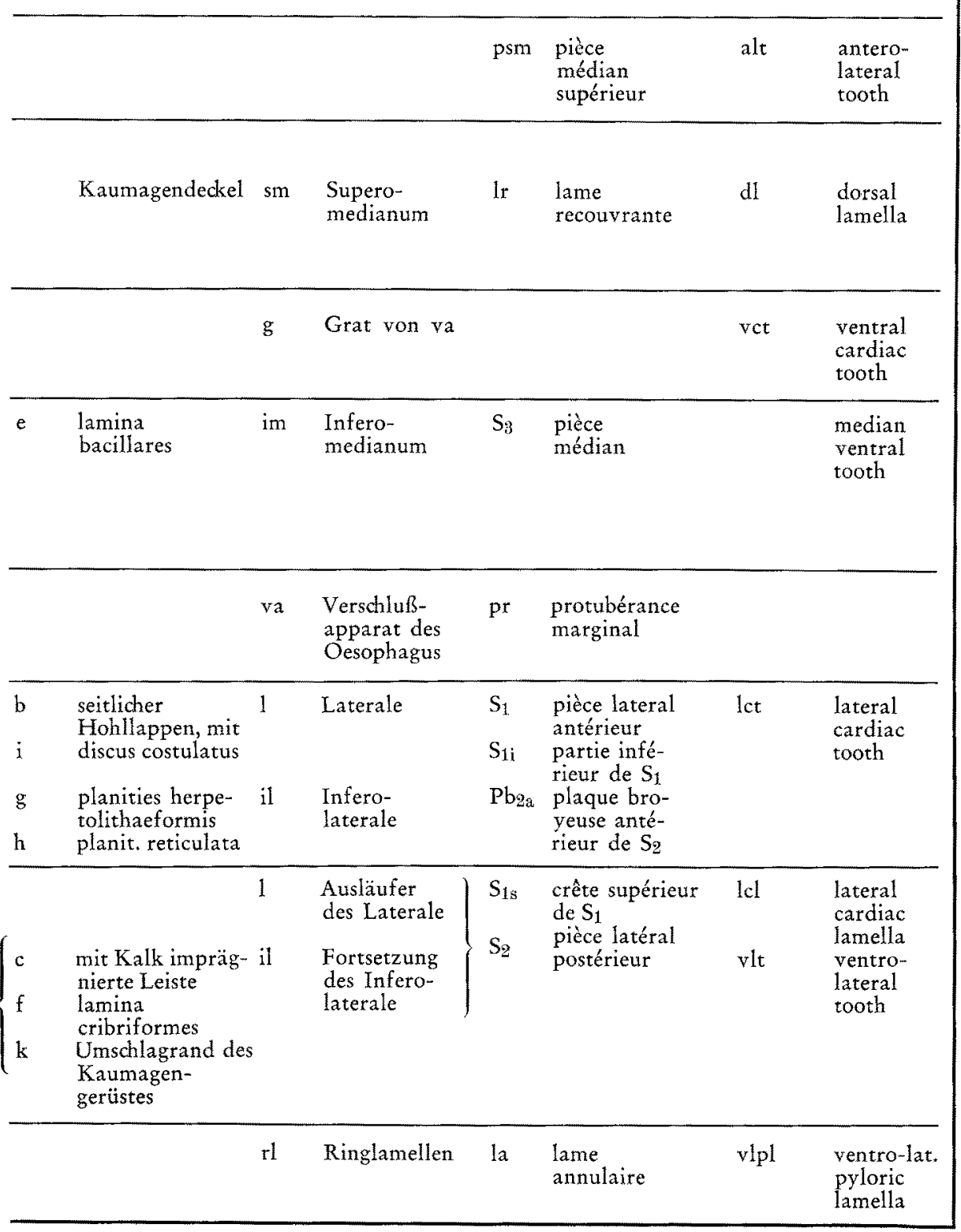


Tabelle 8

\begin{tabular}{|c|c|c|c|c|c|c|c|}
\hline & & & & & $\begin{array}{l}\text { Isopoda } \\
\text { EHORST (1914) }\end{array}$ & & $\begin{array}{l}\text { Isopoda } \\
\text { CHoLLS (1931) }\end{array}$ \\
\hline \multirow{3}{*}{$\begin{array}{l}\overrightarrow{3} \\
\frac{3}{g}\end{array}$} & $\begin{array}{l}\frac{\dot{3}}{0} \\
0 \\
0\end{array}$ & ODK & $\begin{array}{l}\text { Dorsale } \\
\text { Oesophagus- } \\
\text { klappe }\end{array}$ & & & & \\
\hline & 承 & $C D$ & $\begin{array}{l}\text { Cardiakales } \\
\text { Dorsalstück }\end{array}$ & & & maa & $\begin{array}{l}\text { median } \\
\text { anterior } \\
\text { ampulla }\end{array}$ \\
\hline & $\frac{\sum^{n}}{\frac{0}{3}}$ & $\begin{array}{l}\mathrm{PD} \\
\mathrm{PAD}\end{array}$ & $\begin{array}{l}\text { Pylorikales } \\
\text { Dorsalstück } \\
\text { Akzessorisches } \\
\text { Dorsalstïck } \\
\text { des Pylorus }\end{array}$ & $\mathrm{Sm}$ & $\begin{array}{l}\text { Supero- } \\
\text { medianum }\end{array}$ & $\mathrm{dl}$ & $\begin{array}{l}\text { dorsal } \\
\text { lamella }\end{array}$ \\
\hline \multirow[b]{2}{*}{ 蕓 } & : & $\mathrm{CV}$ & $\begin{array}{l}\text { Cardiakales } \\
\text { Ventralstïck }\end{array}$ & $\mathrm{Y}$ & $\begin{array}{l}\text { y-förmiges } \\
\text { Stück }\end{array}$ & $\mathrm{va}$ & $\begin{array}{l}\text { ventral } \\
\text { ampulla }\end{array}$ \\
\hline & $\frac{0}{E}$ & PVK & $\begin{array}{l}\text { Pylorikales } \\
\text { Ventralstück } \\
\text { Pylorikale } \\
\text { Verschluß- } \\
\text { klappe }\end{array}$ & $\mathrm{IM}$ & $\begin{array}{l}\text { Infero- } \\
\text { medianum }\end{array}$ & $\mathrm{vv}$ & $\begin{array}{l}\text { filter } \\
\text { apparatus } \\
\text { ventral } \\
\text { valve }\end{array}$ \\
\hline \multirow{4}{*}{ 莺 } & $\begin{array}{l}\frac{\dot{a}}{0} \\
0.0 \\
0\end{array}$ & OLK & $\begin{array}{l}\text { Laterale } \\
\text { Oesophagus- } \\
\text { klappe }\end{array}$ & & & & \\
\hline & 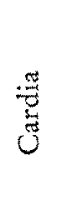 & Cli & $\begin{array}{l}\text { Cardiakales } \\
\text { Laterale } \\
\text { Cardiakales } \\
\text { Inferolaterale }\end{array}$ & IL & $\begin{array}{l}\text { Laterale } \\
\text { Infero- } \\
\text { laterale }\end{array}$ & $\begin{array}{l}\text { la } \\
\text { ala } \\
\text { bp }\end{array}$ & $\begin{array}{l}\text { lateral } \\
\text { ampulla } \\
\text { antero- } \\
\text { lat. amp. } \\
\text { bristle } \\
\text { plate }\end{array}$ \\
\hline & $\frac{\sum_{0}^{\circ}}{3}$ & $\begin{array}{l}\text { PLps } \\
\text { PLpi }\end{array}$ & $\begin{array}{l}\text { Pylorikales } \\
\text { Superolaterale } \\
\text { Pylorikales } \\
\text { Inferolaterale } \\
\text { Oberes } \\
\text { Endstüick } \\
\text { Unteres } \\
\text { Endstïck }\end{array}$ & Ls & $\begin{array}{l}\text { dorsale } \\
\text { Abzweigung } \\
\text { des Laterale } \\
\text { Infero- } \\
\text { laterale }\end{array}$ & $\begin{array}{l}11 \\
\text { avl } \\
\text { vlp }\end{array}$ & $\begin{array}{l}\text { lateral } \\
\text { lamella } \\
\text { anterior } \\
\text { ventral } \\
\text { lamella } \\
\text { projektion } \\
\text { from avl }\end{array}$ \\
\hline & & $\begin{array}{l}\text { PD } \\
+ \\
\text { PLpi }\end{array}$ & & & & $\mathrm{pvl}$ & $\begin{array}{l}\text { posterior } \\
\text { ventral } \\
\text { lamella }\end{array}$ \\
\hline
\end{tabular}


Zusammenfassende Obersicht

\begin{tabular}{|c|c|c|c|c|c|c|c|}
\hline \multicolumn{2}{|r|}{$\begin{array}{l}\text { Euphausiacea } \\
\text { ZmMER (1956) }\end{array}$} & \multicolumn{2}{|c|}{$\begin{array}{c}\text { Decapoda Caridea } \\
\text { PATWARDHAN (1935) }\end{array}$} & \multicolumn{2}{|c|}{$\begin{array}{c}\text { Decapoda Caridea } \\
\text { (Palaemon) } \\
\text { PATWARDHAN (1937) }\end{array}$} & \multicolumn{2}{|c|}{$\begin{array}{l}\text { Decapoda Penaeidea, } \\
\text { Stenopidea } \\
\text { PATWARDHAN (1935) }\end{array}$} \\
\hline $\mathrm{vl}$ & Vorderlippe & & & af & anterior fold & $\mathrm{v}$ & $\begin{array}{l}\text { valve at the } \\
\text { opening of the } \\
\text { cardiac stomach }\end{array}$ \\
\hline ocpk & $\begin{array}{l}\text { obere Cardio- } \\
\text { pylorikalklappe }\end{array}$ & $\mathrm{v} 1$ & $\begin{array}{l}\text { dorsal median } \\
\text { valve }\end{array}$ & v3 & $\begin{array}{l}\text { posterior } \\
\text { valve }\end{array}$ & $\mathrm{mt}$ & median tooth \\
\hline $\mathrm{dsp}$ & Dorsalspange & & & & & & \\
\hline $\begin{array}{l}\text { crst } \\
\text { ucpk }\end{array}$ & $\begin{array}{l}\text { kardiakales } \\
\text { Ventralstück mit } \\
\text { unterer Cardio- } \\
\text { pylorikalklappe }\end{array}$ & $\begin{array}{l}\text { ilr } \\
\text { mtp }\end{array}$ & $\begin{array}{l}\text { internal longi- } \\
\text { tudinal ridge } \\
\text { median trian- } \\
\text { gular plate }\end{array}$ & $\mathrm{hp}_{\mathrm{v} 1}$ & $\begin{array}{l}\text { hastate plate } \\
\text { anterior valve } \\
\text { of the cardio- } \\
\text { pyloric aperture }\end{array}$ & $\begin{array}{l}f \\
\mathrm{cpv}\end{array}$ & $\begin{array}{l}\text { floor of the } \\
\text { card. stomach } \\
\text { cardio-pyloric } \\
\text { valve }\end{array}$ \\
\hline $\begin{array}{l}\text { pyst } \\
z f\end{array}$ & $\begin{array}{l}\text { pylorikales } \\
\text { Ventralstïdk mit } \\
\text { zungenförmigem } \\
\text { Fortsatz }\end{array}$ & fl & $\begin{array}{l}\text { "filter } \\
\text { apparatus }\end{array}$ & $\mathrm{pfp}$ & $\begin{array}{l}\text { pyloric filter } \\
\text { plate }\end{array}$ & & $\begin{array}{l}\text { filtering } \\
\text { apparatus }\end{array}$ \\
\hline z & Zäpfchen & & & & & & $\begin{array}{l}\text { small median } \\
\text { ventral valve }\end{array}$ \\
\hline il & Innenlippe & & & If & lateral fold & & \\
\hline cust & $\begin{array}{l}\text { unteres } \\
\text { cardiakales } \\
\text { Seitenstück }\end{array}$ & $\begin{array}{l}11 \mathrm{f} \\
\mathrm{v} 2\end{array}$ & $\begin{array}{l}\text { lateral longi- } \\
\text { tudinal fold } \\
\text { lateral valve }\end{array}$ & $\begin{array}{l}\mathrm{gr} \\
\mathrm{v} 2\end{array}$ & $\begin{array}{l}\text { lateral longi- } \\
\text { tudinal fold } \\
\text { lateral valve }\end{array}$ & $\begin{array}{l}\text { ilc } \\
\mathrm{zc}\end{array}$ & $\begin{array}{l}\text { infero-lateral } \\
\text { cardiac plate } \\
\text { zygocardiac } \\
\text { ossicle }\end{array}$ \\
\hline $\begin{array}{l}\mathrm{ktr} \\
\mathrm{k}\end{array}$ & $\begin{array}{l}\text { Kammträger mit } \\
\text { Borstenkamm }\end{array}$ & Ilr & $\begin{array}{l}\text { external } \\
\text { longitudinal } \\
\text { ridge }\end{array}$ & $\mathrm{cr}$ & combed plate & $\mathrm{mf}$ & lateral fold \\
\hline $\begin{array}{l}\text { Ist } \\
\text { pust } \\
1\end{array}$ & $\begin{array}{l}\text { dorsaler Flügel } \\
\text { des pust } \\
\text { unteres pylorika- } \\
\text { les Seitenstück } \\
\text { Leiste des } \\
\text { pust }\end{array}$ & & & & & & \\
\hline $\begin{array}{l}\text { osp } \\
\text { usp }\end{array}$ & $\begin{array}{l}\text { obere Spange } \\
\text { des pust } \\
\text { untere Spange } \\
\text { des pust }\end{array}$ & & $\begin{array}{l}\text { pair of elon- } \\
\text { gated valves }\end{array}$ & & & & $\begin{array}{l}\text { pair of elon- } \\
\text { gated valves }\end{array}$ \\
\hline
\end{tabular}


Dorsalstückes $\mathrm{CD}$ an der Magenstirn, Ausprägung des vorderen Abschnittes des Cardiakalen Laterale CLa, Uberschneidung der cardiakalen und pylorikalen Lateralia) mit Merkmalen des Dekapodentypes (Ausbildung des Pylorus, getrennte Ausbildung von Pylorikalem Dorsalstück PD und Unterem Endstück der pylorikalen Seitenwand PLpi, erhöhte Zahl Pylorikaler Filterrinnen PF, Pylorikales Wandfilter PW sowie Form der Pylorikalen Verschlußklappe PVK).

Der $M$ y s idee $n$ m a g n gehört eindeutig zum Dekapodentyp, wenn auch der vordere Teil des Cardiakalen Laterale CLa stark ausgeprägt ist. Eine Sonderstellung nehmen die A m phipoden ein: ihr Magen gehört zwar eindeutig zum Isopodentyp, jedoch ist die Pylorikale Verschlußklappe PVK in der beim Dekapodentyp vertretenen Form ausgebildet. Der Amphipodenmagen ist durch die geschlossene und starke Ausbildung des aus Pylorikalem Dorsalstück und Unterem Endstück der pylorikalen Seitenwand verschmolzenen Stückes PD + PLpi vom Isopodenmagen mit dem Sondermerkmal des Akzessorischen Dorsalstuidkes PAD unterschieden.

In Tabelle 4 wurden die bei den verschiedenen Mägen ausgebildeten Stiicke zusammengefaßt. Dabei wurden die Oesophagusfalten, die bei allen Formen zu finden sind, nur aufgeführt, wenn sie als Oesophagusklappen ausgebildet sind.

\section{ZUSAMMENFASSUNG}

1. Der Kaumagen von Neomysis vulgaris wird als Totalpräparat seiner Chitinintima dargestellt und im einzelnen beschrieben.

2. Zur Erfassung des Oberflächenreliefs im Hinblick auf die Darstellung der Magenmuskulatur wurde das Chitinpräparat in einer Silbersalzlösung durch Reduktion mit einem Überzug aus feinsten Silberpartikeln versehen und damit undurchsichtig gemacht.

3. Die Muskulatur des Labrum wird beschrieben und in Ubersichtsbildern dargestellt. Ein Vergleich mit der Oberlippenmuskulatur von Diastylis ratbkei (Cumacea) ergibt Übereinstimmung für mehrere Muskelzüge.

4. Die Muskulatur des Kaumagens wird beschrieben und in Ubersichtsbildern dargestellt. Ein Vergleich mit der entsprechenden Muskulatur der Decapoda ist nur in sehr beschränktem Umfange möglich; das Ergebnis wurde in Tabelle 3 zusammengestellt.

5. Unter Verwendung von Totalpräparaten der Chintinintima werden die Kaumägen der verschiedenen Vertreter der Eucarida und Peracarida verglichen. Es ergibt sich, daß im Rahmen des gemeinsamen Bauplanes ein Isopodentyp und ein Dekopadentyp ausgeprägt ist, die durch einen $Z$ wischentyp verbunden sind: Die Mägen von Amphipoden, Cumaceen, Tanaidaceen und Isopoden einerseits und die Mägen von Mysideen, Euphausiaceen und Dekapoden andererseits sind durch gemeinsame Merkmale gekennzeichnet, während die Mägen der Lophogastriden Merkmale beider Gruppen vereinigen. 
6. Die Stücke, welche die Magenmühle der Dekapoden zusammensetzen, sind keine Sonderbildung dieser Gruppe, sondern gehören wie die übrigen Teile des Dekapodenmagens dem allgemeinen Bauplan des Malakostrakenmagens an.

Das Thema wurde mir von Herrn Prof. Dr. R. SIEw INg gestellt. Ihm möchte ich auch an dieser Stelle meinen herzlichen Dank sagen für freundlichen Rat und ständige Hilfsbereitschaft während der Durchführung der Arbeit. Herrn Prof. Dr. A. Remane danke ich für die Uberlassung eines Arbeitsplatzes im Zoologischen Institut. Herrn Dr. H. E. GruNER, Institut für Spezielle Zoologie und Zoologisches Museum der Humboldt-Universität Berlin, danke ich für die freundliche Uberlassung zweier Exemplare von Eucopia (Lophogastridea).

\section{ZITIERTE LITERATUR}

Agrawal, V. P., 1963. Functional morphology of the stomach of Corophium volutator Pallas. J. Linn. Soc. (Zool.) 45, 47-52.

Cannon, H. G. \& Manton, S. M., 1927. On the feeding mechanism of a mysid crustacean Hemimysis Lamornae. Trans. R. Soc. Edinb. 55, 219-254.

Claus, C., 1888. Uber Apsendes latreillei und die Tanaiden. Arb. Zool. Inst. Univ. Wien 7, 139-220.

Della Valle, A., 1893. Gammarini. Fauna Flora Golf. Neapel 20, 948 pp.

Gelderd, C., 1909. Research on the digestive system of the schizopoda. Cellule 25, 6-70.

HewrtT, C. G., 1907. Ligia. Proc. Trans. Lpool biol. Soc. 21 (= L. M. B. C. Memoir. 14.), $65-108$.

IDE, M., 1892. Le tube digestif des edriophthalmes. Cellule 8, 99-204.

Jordan, H, 1909. Die Phylogenese der Filtervorrichtungen im Pylorusmagen der Malakostraken. Verh. dt. zool. Ges. 19, 255-266.

- 1913. Vergleichende Physiologie wirbelloser Tiere. Fischer, Jena, 738 pp.

Mathes, I., 1956. Zur systematischen Stellung der Gattung Platyarthrus Brandt. Sber. Akad. Wiss. Wien (Math. K1.) Abt. 1. 165, 81-92.

Maxer, P., 1881/83. Die Caprelliden des Golfes von Neapel. Fauna Flora Golf. Neapel 6, $201 \mathrm{pp}$.

Nicholxs, A. G., 1931. Studies on Ligia oceanica. Pt 2. The progress of feeding, digestion and absorbtion, with a description of the foregut. J. mar. biol. Ass. U. K. 17, 675-705.

Oelze, A., 1931. Beiträge zur Anatomie von Diastylis ratbkei Kr. Zool. Jb. (Anat.) 54, 235-294.

PatWardhan, S. S., 1934. On the structure and mechanism of the gastric mill in decapoda. 1. On the structure of the gastric mill in Paratelpbusa guerini (M.-Edw.). Proc. Indian Acad. Sci. (Sect. B) 1, 183-196.

- 1935. dito. 5. The structure of the gastric mill in Natantous Macrura - Caridea. Proc. Indian Acad. Sci. (Sect. B) 1, 693-704.

- 1935. dito. 6. The structure of the gastric mill in Natantous Macrura - Penaeidea and Stenopidea; Conclusion. Proc. Indian Acad. Sci. (Sect. B) 2, 155-177.

- 1937. Palaemon. The Indian zool. Mem. 6, 100 pp.

Pearson, J., 1908. Cancer, Proc. Trans. Lpool biol. Sac. 22 (= L. M. B. C. Memoir. 16.), 291-499.

Reforst, G., 1914. Der Filtermagen von Asellus aquaticus. Zool. Anz. 44, 228-234.

ScröвL, J., 1860. Typhloniscus, eine neue blinde Gattung der Crustacea Isopoda. Sber. Akad. Wiss. Wien (Math. K1.) 40, 279-330.

Schönichen, W., 1899. Der Darmkanal der Onisciden und Aselliden. Z. wiss. Zool. 65, $143-178$. 
Siewrng, R., 1951. Besteht eine engere Verwandschaft zwischen Isopoden und Amphipoden? Zool. Anz. 147, 166-180.

- 1952. Morphologische Untersudungen an Cumaceen (Cumopsis goodsiri). Zool. Jb. (Anat.) 72, 522-559.

- 1953. Morphologische Untersuchungen an Tanaidaceen und Lophogastriden. Z. wiss. Zool. $157,333-426$.

- 1957. Untersuchungen zur Morphologie der Malacostraca (Crustacea). Zool. Jb. (Anat.) 75, $39-176$.

STAPPERS, L., 1909. Recherches sur le tube digestif des sympodes. Cellule 25, 349-385.

THIEM, E., 1942. Untersuchungen über den Darmkanal und die Nahrungsaufnahme von Synurella ambulans (Amphipoda). Z. Morph. Ökol. Tiere 38, 63-79.

Zrmmer, C., 1956. Euphausiacea. Bronn's Kl. Ordn. Tierreichs 5 (Abt. 1. Buch 6. T. 3), 1-286.

- 1941. Cumacea. Bronn's Kl. Ordn. Tierreichs 5 (Abt. 1. Buch 4. T. 5), 1-222. 